This item was submitted to Loughborough's Research Repository by the author.

Items in Figshare are protected by copyright, with all rights reserved, unless otherwise indicated.

\title{
Dye-sensitized photoelectrochemical cell on plasmonic Ag/AgCl @ chiral TiO2 nanofibers for treatment of urban wastewater effluents, with simultaneous production of hydrogen and electricity
}

\section{PLEASE CITE THE PUBLISHED VERSION}

http://dx.doi.org/10.1016/j.apcatb.2014.11.012

\section{PUBLISHER}

(C) Elsevier

\section{VERSION}

AM (Accepted Manuscript)

\section{PUBLISHER STATEMENT}

This work is made available according to the conditions of the Creative Commons Attribution-NonCommercialNoDerivatives 4.0 International (CC BY-NC-ND 4.0) licence. Full details of this licence are available at: https://creativecommons.org/licenses/by-nc-nd/4.0/

\section{LICENCE}

CC BY-NC-ND 4.0

\section{REPOSITORY RECORD}

Wang, Dawei, Yi Li, Gianluca Li-Puma, Chao Wang, Peifang Wang, Wenlong Zhang, and Qing Wang. 2014. "Dye-sensitized Photoelectrochemical Cell on Plasmonic Ag/agcl @ Chiral Tio2 Nanofibers for Treatment of Urban Wastewater Effluents, with Simultaneous Production of Hydrogen and Electricity”. Loughborough University. https://hdl.handle.net/2134/19052. 


\section{Elsevier Editorial System(tm) for Applied Catalysis B: Environmental}

Manuscript Draft

Manuscript Number: APCATB-D-14-01160R2

Title: Dye-sensitized photoelectrochemical cell on plasmonic Ag/AgCl @ chiral TiO2 nanofibers for treatment of urban wastewater effluents, with simultaneous production of hydrogen and electricity

Article Type: Research Paper

Keywords: Wastewater treatment; Dye-sensitized photoelectrochemical cell; Hydrogen production; Electricity generation; Ag/AgCl @ chiral TiO2 nanofibers

Corresponding Author: Prof. Gianluca LI Puma, PhD

Corresponding Author's Institution: Loughborough University

First Author: Dawei Wang

Order of Authors: Dawei Wang; Yi Li, PhD; Gianluca LI Puma, PhD; Chao Wang; Peifang Wang;

Wenlong Zhang; Qing Wang 
1 Dye-sensitized photoelectrochemical cell on plasmonic

2 Ag/AgCl @ chiral $\mathrm{TiO}_{2}$ nanofibers for treatment of urban

3 wastewater effluents, with simultaneous production of

$4 \quad$ hydrogen and electricity

5 Dawei Wang ${ }^{a}$, Yi Li ${ }^{a} *$, Gianluca Li Puma ${ }^{b}$, Chao Wang ${ }^{a}$, Peifang Wang ${ }^{a}$, Wenlong

6 Zhang $^{a}$ and Qing Wang ${ }^{a}$

7

${ }^{a}$ Key Laboratory of Integrated Regulation and Resource Development of Shallow

9 Lakes, Ministry of Education, College of Environment, Hohai University. Xi Kang

Road \#1, Nanjing 210098, PR China; E-mail: envly@hhu.edu.cn (Corresponding

11

12

Author 1)

${ }^{b}$ Environmental Nanocatalysis \& Photoreaction Engineering, Department of Chemical

Engineering, Loughborough University, Loughborough LE11 3TU, United Kingdom;

E-mail: g.lipuma@lboro.ac.uk (Corresponding Author 2)

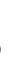
7 8 


\section{$1 \quad$ Abstract}

2 The feasibility of simultaneous production of hydrogen and electricity with

3 simultaneous contaminants removal from "actual" urban wastewater within a

4 dye-sensitized photoelectrochemical cell (DSPC) is demonstrated for the first time. The

5 photoanode in the DSPC was a novel nanostructured plasmonic $\mathrm{Ag} / \mathrm{AgCl} @$ chiral

$6 \mathrm{TiO}_{2}$ nanofibers (Ag and $\mathrm{AgCl}$ nanoparticles supported on chiral $\mathrm{TiO}_{2}$ nanofibers). The

7 electrolyte in the DSPC was actual wastewater to which an estrogen

8 (17- $\beta$-ethynylestradiol, EE2) and a heavy metal $\left(\mathrm{Cu}^{2+}\right)$ were added. The contaminants

9 in the wastewater rather than $\mathrm{I}^{-} / \mathrm{I}_{3}{ }^{-}$(usual electrolyte in conventional DSPCs) acted as electrons bridges for the stabilization of charges in this DSPC. Almost total removal of total organic carbon (TOC), $\mathrm{Cu}^{2+}, \mathrm{EE} 2$, and $70 \%$ removal of total nitrogen $(\mathrm{TN})$ were achieved under visible-light irradiation. A relatively high solar energy conversion efficiency (PCE 3.09\%) was recorded and approximately $98 \%$ of the electricity was converted to $\mathrm{H}_{2}$ after the consumption of dissolved oxygen (DO), $\mathrm{Cu}^{2+}$ and TN. This performance was attributed to the "symbiotic" relationship between the $\mathrm{TiO}_{2}$ chiral nanofibers and the plasmonic effect of Ag nanoparticles at the photoanode although Ag acting as a recombination site may hinder the generation of electricity. The dye N719 in this study exhibited a temporary sensitization effect, and a more efficient sensitizer is expected to be studied in the future. This study opens up new opportunities for producing renewable energy from wastewater treatment processes including organic and inorganic matter as viable resources. 


\section{Keywords:}

2 Wastewater treatment; Dye-sensitized photoelectrochemical cell; Hydrogen production;

3 Electricity generation; $\mathrm{Ag} / \mathrm{AgCl} @$ chiral TiO $\mathrm{O}_{2}$ nanofibers

\section{1. Introduction}

5 Energy crisis and increasing environmental pollution are two of the greatest threats to human population sustainability at a global scale. Within this wide contest, wastewater

7 previously considered as a waste is increasingly being used as a valuable resource for 8 producing fresh water, energy and fertilizing nutrients $(\mathrm{N}$ and $\mathrm{P})$. For instance, the

9 wastewater's organic content can be converted into methane gas through the anaerobic process [1], and microbial fuel cell (MFC) [2,3] may also be a viable route for the production of energy from wastewater treatment. Photocatalytic oxidation using titanium dioxide $\left(\mathrm{TiO}_{2}\right)$ is an effective method for the removal of chemically stable contaminants, it requires no chemicals input or output and $\mathrm{TiO}_{2}$ is inexpensive and non-toxic [4-8]. The photocatalytic oxidation of contaminants is initiated by the excitation of $\mathrm{TiO}_{2}$, which results in the promotion of an electron (e-) to the conduction band $(\mathrm{CB})$ and creation of a hole $(\mathrm{h}+)$ in the valence band (VB) of $\mathrm{TiO}_{2}$ [9]. The photogenerated electrons and holes produce highly reactive oxygen species (ROS) (i.e. $\mathrm{H}_{2} \mathrm{O}_{2}, \mathrm{HO} \cdot, \mathrm{O}_{2} \cdot{ }^{-}$) which can attack and oxidize organic contaminants, ultimately leading to complete mineralization.

The utilization of freely available solar energy as the only energy input makes photocatalysis a sustainable and green process. However, one of the most important 
1 advancement in wastewater treatment should be the development of a new process that

2 can simultaneously capture the chemical energy of the oxidized contaminants while

3 meeting the effluent quality standards [1]. Although the appeal of the direct conversion

4 of solar into chemical energy during a wastewater treatment process has been

5 recognized for a long time, effective efforts are still rare. Recently, a series of studies

6 have succeeded in using some organic fractions in wastewater (i.e. phenolic

7 compounds and dyes) to act as electron donors for producing $\mathrm{H}_{2}[11,12]$ and for

8 electricity generation [13], and our group has reported the feasibility of hydrogen

9 generation during the removal of emerging contaminants [14, 15]. Very few studies

10 have focused on the harvesting of energy during the removal of both organic and

11 inorganic compounds (e.g. nutrients) in contaminated water and wastewater, making

12 this the main scientific and technological challenge for the water industry. In this study,

13 inspired by the PhotoFuelCell system proposed by Lianos and coworkers [16-19], we

14 demonstrate that dye-sensitized photoelectrochemical cells (DSPCs) may be valuable

15 to address this technological issue.

The concept of DSPCs was similar with that of dye-sensitized solar cells (DSSCs). In a

DSSC, the sensitizer, which is usually a dye, absorbs the incident photons resulting in the excitation of electrons from the highest occupied molecular orbital (HOMO) to the lowest unoccupied molecular orbital (LUMO) of the dye. The excited electrons are then injected to the conduction band $(\mathrm{CB})$ of the photoanode material (usually $\mathrm{TiO}_{2}$ ), they further transfer to the photoanode fluorine-doped tin oxide (FTO) supporting the $\mathrm{TiO}_{2}$ and through the external load, travel to the cathode FTO and to the cathode material 
1 (usually a Pt layer). They then transfer to the HOMO of the redox couples (usually

$2 \mathrm{I}^{-} / \mathrm{I}_{3}{ }^{-}$), and finally back to the HOMO of the dye $[20,21]$ to close the cycle. In this

3 process, the redox couples play a very important role as electrons bridges for the

4 stabilization of charges in the DSSCs. One major innovating aspect of the present study

5 is the replacement of the redox couples (such as $\mathrm{I}^{-} / \mathrm{I}_{3}{ }^{-}$) in DSSCs with organic and

6 inorganic compounds naturally occurring in urban wastewater, which collectively can

7 act as an effective electrolyte and also reduced the dye in excited state to stable state.

8 Although dyes have been reported to be unstable in water, they may have a temporary

9 sensitization effect. Under an ideal situation, organic contaminants may be oxidized by an excited dye in the photoanode, while nitrate and heavy metal could be reduced in the

11 cathode (Fig. 1) including the reduction of protons into $\mathrm{H}_{2}$.

12 The $\mathrm{DSPC}$ with $\mathrm{Ag} / \mathrm{AgCl} @$ chiral $\mathrm{TiO}_{2}$ nanofibers as photoanode material, a 13 platinized FTO sheet as a counter electrode and actual urban wastewater as electrolyte 14 was investigated for the first time for the simultaneous generation of electricity, 15 hydrogen gas and for simultaneous removal of contaminants from wastewater, 16 including 17- $\beta$-ethynylestradiol (EE2) as a representative of chemically stable and 17 emerging contaminants which was added to the wastewater. The performance and the underlying mechanisms of this highly innovating concept for environmental 19 remediation with simultaneous generation of renewable energy are presented in this 20 study. 


\section{Materials and Methods}

\subsection{Synthesis of $\mathrm{Ag} / \mathrm{AgCl} @$ chiral $\mathrm{TiO}_{2}$ nanofibers photoanode}

Chiral $\mathrm{TiO}_{2}$ nanofibers were synthesized with $\mathrm{N}$-(1-oxooctadecyl)-D-glutamic acid $\left(\mathrm{C}_{18}\right.$-D-Glu $)$ as template and details can be found in our previous study [22]. In a typical synthesis, C18-D-Glu (0.06 g, $0.16 \mathrm{mmol})$ was dissolved in a mixture of methanol (27.2 g) and deionized water $(160 \mathrm{ml})$ while stirring at room temperature. After the mixture was stirred for $10 \mathrm{~min}, \mathrm{TDA}(0.58 \mathrm{~g}, 75 \%$ in isopropanol, purchased from TCI) was added to the mixture with stirring at $55^{\circ} \mathrm{C}$. The mixture was allowed to react at $55^{\circ} \mathrm{C}$ with stirring for $2 \mathrm{~h}$. The products were collected by centrifugal separation and dried by freeze drying at $-60{ }^{\circ} \mathrm{C}$, which resulted in a pale yellow powder. All organics in this product were removed by calcination at $550{ }^{\circ} \mathrm{C}$, and crystalline anatase was obtained.

Then, the as-prepared pure chiral $\mathrm{TiO}_{2}$ nanofibers were used to fabricate $\mathrm{Ag} / \mathrm{AgCl} @$ chiral $\mathrm{TiO}_{2}$ nanofibers. In a typical synthesis of $\mathrm{Ag} / \mathrm{AgCl} @$ chiral $\mathrm{TiO}_{2}$ nanofibers, pure chiral $\mathrm{TiO}_{2}$ nanofibers $(0.2 \mathrm{~g})$ and cetyltrimethylammonium chloride $(0.3 \mathrm{~g}$, purchased from TCI) were added into deionized water $(100 \mathrm{~mL})$ while stirring at room temperature. After the mixture was stirred for $60 \mathrm{~min}, \mathrm{AgNO}_{3}(2.0 \mathrm{~mL}, 0.1 \mathrm{M})$ was quickly added into the mixture. The resulting solution was stirred at room temperature for further $60 \mathrm{~min}$ and irradiated with an $8 \mathrm{~W}$ UVC light for $40 \mathrm{~min}$. The suspension was collected by centrifugal separation and then dried at $80{ }^{\circ} \mathrm{C}$ for $8 \mathrm{~h}$, which resulted in a brown powder. Finally, the powder was calcined at $300{ }^{\circ} \mathrm{C}$ in air and $\mathrm{Ag} / \mathrm{AgCl} @$ chiral $\mathrm{TiO}_{2}$ nanofibers were obtained. Chiral $\mathrm{TiO}_{2}$ nanofibers were also physically broken 
1 with the application of pressure at $10 \mathrm{MPa}$ using FTIR tablet press (to avoid changes of

2 the $\mathrm{TiO}_{2}$ morphological structures) prior to the deposition of $\mathrm{Ag} / \mathrm{AgCl}$, to prepare

$3 \mathrm{Ag} / \mathrm{AgCl} @$ broken chiral $\mathrm{TiO}_{2}$ nanofibers. The synthesis of $\mathrm{Ag} / \mathrm{AgCl} @$ broken chiral

$4 \quad \mathrm{TiO}_{2}$ nanofibers was carried out under the same conditions used to prepare the $\mathrm{Ag} / \mathrm{AgCl}$

$5 @$ chiral $\mathrm{TiO}_{2}$ nanofibers, to ensure that an equal amount of $\mathrm{Ag} / \mathrm{AgCl}$ was deposited on

6 the same amount of chiral $\mathrm{TiO}_{2}$ nanofibers and broken chiral nanofibers.

\section{2.2. Assembly of DSPCs}

8 The $\mathrm{Ag} / \mathrm{AgCl} @$ chiral $\mathrm{TiO}_{2}$ nanofibers photoanode was prepared by adding $6 \mathrm{~g}$ of PVA

9 (MW 22000, purchased from TCI) into $14 \mathrm{~mL}$ of boiled distilled water with powerful stirring, producing a highly viscous liquid that was further diluted by adding to a solvent made of $18 \mathrm{~mL}$ distilled water and $25 \mathrm{~mL}$ ethanol at $70{ }^{\circ} \mathrm{C}$. Then, $1.62 \mathrm{~g}$ of the as-prepared $\mathrm{Ag} / \mathrm{AgCl} @$ chiral $\mathrm{TiO}_{2}$ nanofibers were added into the PVA/water/ethanol solution to produce a suspension which was then left to cooled to room temperature. The photoanode films were produced on FTO glass $\left(2.3 \mathrm{~mm}\right.$ thickness, $25 \mathrm{~cm}^{2}$ area, 8 $\Omega$ /sq, Dyesol Glass, previously cleaned with 2-propanol in an ultrasonic bath for 30 min, and then thoroughly rinsed with distilled water, followed by drying on nitrogen) by coating a paste of the suspension using the doctor-blade technique [23]. After coating the films were kept in a clean box for 15 min to relax surface irregularities and the residual mechanical stress of the coating. Finally, the photoanode was gradually heated at $80{ }^{\circ} \mathrm{C}$ for $15 \mathrm{~min}$ and then at $500{ }^{\circ} \mathrm{C}$ for $30 \mathrm{~min}$. The thickness of the film $(11$ $\mu \mathrm{m})$ was increased by repeating this doctor-blade technique [24]. For the preparation of the counter electrode, a drop of $5 \mathrm{mM} \mathrm{H}_{2} \mathrm{PtCl}_{6} \cdot \mathrm{H}_{2} \mathrm{O}$ in 2-propanol was placed on the 
1 FTO glass substrate $\left(25 \mathrm{~cm}^{2}\right.$ area), following by drying and annealing at $450{ }^{\circ} \mathrm{C}$ for 30

$2 \min$.

3 The photoanode was impregnated with the dye by immersion into a 1:1 (v/v) mixture of

4 acetonitrile (CR, Sigma-Aldrich) and tert-butanol (CR, Sigma-Aldrich) containing a

$5 \quad 0.5 \mathrm{mM}$ N719 (Dyesol) dye solution for $6 \mathrm{~h}$. Then, the dye-loaded photoanode was

$6 \quad$ washed with acetonitrile and dried with nitrogen.

7 The DSPCs were assembled into a sandwich design using the dye loaded photoanode

8 and the cathode. The distance between the two electrodes was $5 \mathrm{~mm}$. The gap between

9 the electrodes was filled with actual wastewater collected from the effluent of a municipal wastewater treatment plant in Suzhou (China) with further addition (0.56

$11 \mathrm{mg} / \mathrm{L}$ ) of 17- $\beta$-ethynylestradiol (EE2) (HPLC grade, Merck) and $\mathrm{CuSO}_{4}(1.03 \mathrm{mg} / \mathrm{L})$.

12 The chemical properties of the wastewater effluent are presented in Table S1 13 (Supplementary Material). The $\mathrm{pH}$ of the wastewater in the DSPCs was adjusted using $141 \mathrm{~mol} / \mathrm{L} \mathrm{H}_{2} \mathrm{SO}_{4}$.

\subsection{Instruments and experimental conditions}

Scanning electron microscopy (SEM) images were obtained with a JEOL JSM-7041F at an accelerating voltage of $1 \mathrm{kV}$. Large scope EDX analysis was conducted on an energy dispersive X-ray spectrometer (ZAF Quantification) attached to the SEM of JEOL JSM-7041F. Transmission electron microscopy (TEM) was performed on a JEOL 2011 operation at $200 \mathrm{kV}$. X-ray diffraction (XRD) patterns were recorded on a Rigaku X-ray diffractometer D/MAX-2200/PC equipped with $\mathrm{Cu} K \alpha$ radiation $(40 \mathrm{kV}$, $20 \mathrm{~mA}$ ). X-ray photoelectron spectroscopy (XPS) results were obtained with PHI 
$15000 \mathrm{C}$ ESCA with $\mathrm{Mg} K \alpha$ source operating at $14 \mathrm{kV}$ and $25 \mathrm{~mA}$. UV-vis diffuse

2 reflectance spectroscopy was performed in triplicate on similar samples to ensure

3 reproducibility, on a SHIMADZU UV-2450 with a collection speed of $40 \mathrm{~nm} \mathrm{~min}{ }^{-1}$

$4 \mathrm{BaSO}_{4}$ as the reference. All samples were obtained by scratching films off the FTO

5 substrates and degassing at $200{ }^{\circ} \mathrm{C}$ overnight.

6 Prior to irradiation, twelve fabricated DSPC cells (the volume of each cell was 12.5

7 were vertically fixed into an oscillation box, and were all shaken in the dark, for 40

8 to establish adsorption-desorption equilibrium of the solution species with the

9 electrodes. Then water samples for analysis were taken when all 12 cells were irradiated for two hours using an AM 1.5 solar simulator (Oriel) equipped with a 150

11 xenon light and AM 1.5G type filter (Newport, 81094). It should be noted that 12 for analyses were collected at 10-min interval sequentially from ordered DSPCs (e.g. sample \#1 was collected from cell \#1 at $\mathrm{t}=0$, sample \#2 was collected from cell \#2 at $14=10 \mathrm{~min}$, etc.) since the liquid volume in each cell was small and repeated sampling only from one cell would interfere with the cell performance. The current-voltage $(J-V)$ characteristics of the 12 cells were measured as described elsewhere [24]. The amount of hydrogen, the concentrations of EE2, TOC, TN and DO were measured as shown our previous studies $[4,14,25]$. Briefly, the concentration of EE2 was detected by High Performance Liquid Chromatography (HPLC, Agilent 1100). TOC was measured by means of a Shimadzu TOC-V VPN with an ANSI-V auto sampler. TN was measured using multi N/C 2100 TOC analyzer (Analytikjena, Germany). DO was monitored with electrode for DO sensor (UC-12-SOL, Central Kagaku Co.). The gas 
1 produced was collected by water displacement method using sulfuric acid (2\%) and

$2 \mathrm{NaCl}(10 \%)$ containing solution and then measured using a gas chromatograph (HP

3 Agilent, 6890) equipped with a thermal conductivity detector and a molecular sieve

45 A column.

\section{3. Results and Discussion}

\section{3.1. Characterization of $\mathrm{Ag} / \mathrm{AgCl} @$ chiral $\mathrm{TiO}_{2}$ nanofibers}

7 SEM pictures of the $\mathrm{Ag} / \mathrm{AgCl} @$ chiral $\mathrm{TiO}_{2}$ nanofibers (Fig. 2a) revealed that the

8 left-handed, double-helical morphology was preserved after the deposition of the Ag

9 and $\mathrm{AgCl}$ nanoparticles. The average length of undamaged $\mathrm{TiO}_{2}$ nanofibers was $\sim 500$ $\mathrm{nm}$ and diameter was $\sim 20 \mathrm{~nm}$. TEM analyses (Fig. 2b-c) revealed that $\mathrm{Ag} / \mathrm{AgCl}$ nanoparticles with the average diameters of 5-8 $\mathrm{nm}$ were deposited on the surface of the chiral $\mathrm{TiO}_{2}$ nanofibers, preferentially at the outer edges of the $\mathrm{TiO}_{2}$ crystals of the helical structure, following the conceptual structure shown in Fig. 2d.

The elemental and chemical compositions of the samples were further determined by XPS. The results (Fig. S1a, Supplementary Material) suggest that $\mathrm{Ag} / \mathrm{AgCl} @$ chiral $\mathrm{TiO}_{2}$ nanofibers contain $\mathrm{Ti}, \mathrm{O}, \mathrm{C}, \mathrm{Ag}$ and $\mathrm{Cl}$ elements. The $\mathrm{C} 1 \mathrm{~s}$ was attributed to the adventitious hydrocarbon released from the XPS instrument [23]. In Fig. S1b (Supplementary Material), the Ag 3d spectra consists of two individual peaks approximately at 373 and $367 \mathrm{eV}$, which are due to $\mathrm{Ag} 3 \mathrm{~d}_{3 / 2}$ and $\mathrm{Ag} 3 \mathrm{~d}_{5 / 2}$ binding energy, respectively. The existence of $\mathrm{Ag}^{0}$ and $\mathrm{Ag}^{+1}$ could be verified by further peaks divisions [24]. Consequently, the XPS analyses suggested that the nanoparticles 
1 deposited on chiral $\mathrm{TiO}_{2}$ nanofibers were made of $\mathrm{Ag} / \mathrm{AgCl}$ composites. The

2 elemental composition determined by EDX (Fig. S2, Supplementary Material),

3 resulted in a $\mathrm{Ag}$ content of $5.49 \mathrm{~mol} \%$ and a $\mathrm{Cl}$ content of $2.86 \mathrm{~mol} \%$, which

4 indicated that the $\mathrm{Ag} / \mathrm{AgCl}$ was virtually at a $1: 1$ molar ratio. XRD results also

5 suggested the co-existence of $\mathrm{Ag}$ and $\mathrm{AgCl}$ (Fig. S3 and detailed descriptions in

6 Supplementary Material). Further details on material characterization have been

7 reported [22]. Moreover, the chiral nanostructure was preserved after the doctor-blade

8 process although some aggregation of the nanofibers was observed (Fig. 3).

\section{3.2. Contaminants removal in the DSPC}

EE2 representing for chemically stable organic compounds $\mathrm{Cu}^{2+}$ representing for heavy metal ions were spiked into the wastewater at specific concentrations to investigate the removal of contaminants (TOC, TN, EE2 and $\mathrm{Cu}^{2+}$ ) in the cell were spiked into the wastewater at specific concentrations to investigate the removal of contaminants (TOC, TN, EE2) in the cell (Fig. 4). TOC, $\mathrm{Cu}^{2+}$ and EE2 were totally removed after $80 \mathrm{~min}$, while only approximately $70 \%$ of TN was removed within 120 min. Meanwhile, a decrease of DO over time was observed, indicating the mineralization of TOC and EE2 is aerobic [15]. The fast photodegradation of the TOC including EE2 should be attributed to the combined effect of (i) the strong photocatalytic activity of irradiated $\mathrm{Ag} / \mathrm{AgCl} @$ chiral $\mathrm{TiO}_{2}$ nanofibers and of (ii) the oxidization ability of sensitized dyes. Regarding the first effect, $\mathrm{Ag} / \mathrm{AgCl} @$ chiral $\mathrm{TiO}_{2}$ nanofibers under visible-light irradiation produces photogenerated electron-hole pairs in the Ag nanoparticles due to surface plasmon resonance (SPR) [26]. In this 
1 process, SPR generates the electron-hole pairs in the semiconductor $\left(\mathrm{AgCl}\right.$ and $\left.\mathrm{TiO}_{2}\right)$

2 by the dipole-dipole interaction between the donor $(\mathrm{Ag})$ and the acceptors $(\mathrm{AgCl}$ and

$\left.3 \mathrm{TiO}_{2}\right)$. The photocatalytic activity of $\mathrm{Ag} / \mathrm{AgCl} @$ chiral $\mathrm{TiO}_{2}$ nanofibers should

4 mainly be attributed to two simultaneous processes. The strong electronic coupling

5 between $\mathrm{Ag}$ and $\mathrm{AgCl}$ conduction bands which injects photoinduced electrons from

6 the $\mathrm{Ag}$ nanoparticles, quickly and efficiently, into the $\mathrm{AgCl}$ [27] and into the $\mathrm{TiO}_{2}$

7 helical structure, probably yielding superoxide radicals and finally $\mathrm{HO}$. radicals from

8 the reductive pathway, as reported with other dyes [28]. However, this effect seems

9 negligible for the removal of the contaminants since the direct charge transfer from

10 noble nanoparticles or the internal photoemission from $\mathrm{TiO}_{2}$ and $\mathrm{AgCl}$ [29] only play

11 a supporting role in the photoelectrical performance. This was verified of the $J-V$

12 characteristics of the solar cells not sensitized without dye N719 (see Fig S5).

13 Regarding the effect of the sensitized dye on the removal of TOC and EE2, the redox 14 potential of N719/sensitized N719 is 1.1 V (vs. normal hydrogen electrode (NHE))

15 [21] and sensitized N719/oxidized N719 is -0.6 V (vs. NHE) [30] which is sufficient

to oxidize most organic compounds in wastewater, since their redox potentials were mostly less than $0.6 \mathrm{~V}$ vs. NHE [31]. As a result, the reduction of the sensitized dye to its ground state maintained the cell cycle until all organic contaminants were removed from the wastewater. Since the synthesized wastewater was acid, the decrease in the TN should be attributed to the reduction of $\mathrm{NO}_{3}{ }^{-}$of the wastewater by the electrons transferred to the photocathode: 
$1 \quad \mathrm{NO}_{3}^{-}+4 \mathrm{H}^{+}+3 \mathrm{e}^{-} \rightarrow \mathrm{NO}+\mathrm{H}_{2} \mathrm{O} \quad \mathrm{E}^{0}=0.9637 \mathrm{~V}$

2 This significant mass deficit in the TN balance also confirms some gaseous product

3 such as $\mathrm{NO}$ and $\mathrm{N}_{2} \mathrm{O}$ are generated as a result of $\mathrm{NO}_{3}{ }^{-}$reduction. The $30 \%$ of TN

4 survived from the photoelectrical degradation should be $\mathrm{NH}_{3}-\mathrm{N}$ as they cannot be

5 reduced in acid or neutral conditions [32].

6 3.3. Photoelectrical performance and hydrogen generation of the DSPC

7 SPR is characterized by a build-up of intense, spatially non-homogeneous oscillating

8 electric fields in the neighbourhood of the nanostructure [22]. The SPR effect at the

9 photoanode improves the efficiency of the DSPCs by (1) increased light absorption due to surface plasmons and light-trapping effects, (2) improved charge separation as a result of the localized electro-magnetic field, (3) the promotion of electron transfer to adsorbed species, and (4) the electron storage effect that can shifts the Fermi level to more negative potentials [33-36]. Although the direct charge transfer from $\mathrm{Ag}$ nanoparticles to the semiconductor may also prove useful for the electricity generation as mentioned above, the main mechanism of photo-excitation of the photoanode with visible light implies the sensitization of the N719 dye, and the transfer of excited electrons to the $\mathrm{Ag} / \mathrm{AgCl} @$ chiral $\mathrm{TiO}_{2}$ nanofibers, the external load, the counter cathode and lastly the simultaneous reductions of $\mathrm{NO}_{3}{ }^{-}, \mathrm{H}^{+}$and $\mathrm{Cu}^{2+}$. The presence of metallic $\mathrm{Cu}$ on the surface of the counter electrode after the process was further substantiated by two XPS peaks at $932.6 \mathrm{eV}$ and $952.5 \mathrm{eV}$ (Fig. S4, Supplementary Material). In parallel to the above mechanism, the sensitized N719 dye is reduced back to its ground state by the adsorbed organic matter and nitrogen, 
1 which were present in the wastewater, therefore, sacrificial organic and inorganic

2 matter are essential to sustain the mechanism of the DSPCs. This mechanism is

3 further exemplified by the current-voltage $(J-V)$ and current-power densities $(J-P)$

4 plots, which were recorded to investigate the electrical performance of the cell (Fig.

5 5). The short-circuit current densities $\left(J_{s c}\right)$, open-circuit voltage $\left(V_{o c}\right)$ and power

6 densities varied with time during the irradiation of DSPCs. $J_{s c}$ decreased significantly

7 over time and it even turned to be $0.02 \mathrm{~mA} / \mathrm{cm}^{2}$ after $80 \mathrm{~min}$ and then remained stable,

8 while $V_{o c}$ just showed slight decrease (Table S2). These should be attributed to the

9 removal of contaminants in the cell as they functioned as electrons bridges. Moreover,

$J_{s c}$ is determined by electron injection $[20,35]$ which depends on the concentration of

11 contaminants, hence, $J_{s c}$ decreased eventually to a relatively low level as the

12 contaminants were totally removed, after $80 \mathrm{~min}$. However, $J_{s c}$ did not decrease to 0

13 as expected, this may be due to Ag can also be excited by visible-light irradiation

14 while $\mathrm{TiO}_{2}$ can be excited by the small fraction of UV accessible under AM 1.5

15 irradiation, and also produced electron-hole pairs [33]. Then the produced electrons

transferred through external load to counter photocathode while the holes may react with $\mathrm{H}_{2} \mathrm{O}$. This is consistent with the photoelectrical performances of the solar cells not sensitized with N719 (Fig. S5, Supplementary Material). Meanwhile, these produced holes may also oxidize some N719 molecules and disable this DSPC (this will be discussed in following section). In contrast, $V_{o c}$ is largely affected by the properties of the photoanode, i.e., the conductive band potential of the photoanode and the dye absorption number [36], thus $V_{o c}$ decreased. 
1 The characterization of the cell under dark conditions is shown in Fig. S6

2 (Supplementary Material). The dark currents observed due to the presence of $\mathrm{CuSO}_{4}$

$3\left(J_{s c}\right.$ of $\left.0.016 \mathrm{~mA} / \mathrm{cm}^{2}\right)$ were insignificant in comparison with the currents observed

4 under irradiation (Fig. 5). $\mathrm{Cu}^{2+}$ is practically removed from the aqueous solution in

$540 \mathrm{~min}$ (Fig. 4) to which corresponds a $J_{s c}$ of $4.59 \mathrm{~mA} / \mathrm{cm}^{2}$.

6 The fill factors (Table 1) were calculated according to [16,37]:

$7 \quad f f=\frac{P_{\max }}{J_{s c} V_{o c}}$

8 where $P_{\max }$ is the maximum power density.

9 Fig. 6 shows the photogeneration of $\mathrm{H}_{2}$ over time in the DSPCs. The electrons

transferred to the counter electrodes reduced protons to $\mathrm{H}_{2}$, although some $\mathrm{H}_{2}$ could also be formed during the degradation of organic matter $[11,38]$. The $\mathrm{H}_{2}$ production was not observed until 40 min $c a$., when DO and $\mathrm{Cu}^{2+}$ were almost totally consumed (Fig. 4) as the redox potentials of $\mathrm{Cu}^{2+} / \mathrm{Cu}(0.3394 \mathrm{~V}$ vs. NHE) and the redox potentials of $\mathrm{O}_{2} / \mathrm{H}_{2} \mathrm{O}\left(1.229 \mathrm{~V}\right.$ vs. NHE) were higher than that of $\mathrm{H}^{+} / \mathrm{H}_{2}(0$ vs. NHE $)$ [39]. In agreement with the electrical performance, the rate of $\mathrm{H}_{2}$ production gradually decreased as the concentration of contaminants decreased and reached approximately zero, after $80 \mathrm{~min}$, when the electricity was only generated due to the excitation of $\mathrm{TiO}_{2}$ and $\mathrm{Ag}$ under irradiation.

The photo-electricity conversion efficiency (PCE) was calculated (Table S2) to evaluate the photoelectrical performance of the DSPC. An efficiency of 3.09\% was recorded at 0 min, indicating $3.09 \%$ of the incident light energy was converted into electricity. Moreover, the electricity-hydrogen conversion efficiency (ECE) was 
$2 \quad E C E(\%)=\frac{E_{\mathrm{H}_{2}}}{E_{\mathrm{el}}}=\frac{2 n_{t} U}{\int P_{\max } A d t} \times 100$

3 where $E_{\mathrm{H}_{2}}$ is the $\mathrm{H}_{2}$ energy $(\mathrm{J})$ produced by the cell, $E_{\mathrm{el}}$ is generated electricity

4 energy on the photoanode $(\mathrm{J}), P_{\max }$ is the maximum power density $\left(\mathrm{W} / \mathrm{cm}^{2}\right), \quad A$ is the

5 irradiated surface area of photoanode $\left(\mathrm{cm}^{2}\right), n$ is the total amount of hydrogen

6 produced (mol), $U$ is the hydrogen energy content $(122 \mathrm{~kJ} / \mathrm{g}$ ) and $t$ is time (s). As

7 shown in Table S2, 78.1\% of the electricity generated from 40 to 50 min was

8 converted to hydrogen energy. While after $60 \mathrm{~min}$, approximately $98 \%$ of the

9 electricity was converted due to the total removal of $\mathrm{NO}_{3}{ }^{-}$in the wastewater.

\subsection{Chirality and plasmonic effect in the DSPC}

The highest PCE in this study was $3.09 \%$ which is relatively high considering the electrolyte was actual wastewater rather than $\mathrm{I}^{-} / \mathrm{I}_{3}{ }^{-}$solution. This supports the superior performance of $\mathrm{Ag} / \mathrm{AgCl} @$ chiral $\mathrm{TiO}_{2}$ nanofibers as photoanode in the DSPC. Herein, the photoanodes prepared with chiral $\mathrm{TiO}_{2}$ nanofibers, $\mathrm{Ag} / \mathrm{AgCl} @$ broken chiral $\mathrm{TiO}_{2}$ nanofibers served as references, to exemplify the chiral plasmonic effect on the performance of the DSPC. The SEM and TEM pictures of these reference photoanode are shown in Fig. S7 (Supplementary Material). The absorption spectrums of $\mathrm{Ag} / \mathrm{AgCl} @$ chiral $\mathrm{TiO}_{2}$ nanofibers thin film and other reference photoanode thin films are shown in Fig. S8 (Supplementary Material). The stronger absorption of $\mathrm{Ag} / \mathrm{AgCl} @$ chiral $\mathrm{TiO}_{2}$ nanofibers at $200-350 \mathrm{~nm}$ compared to pure chiral $\mathrm{TiO}_{2}$ nanofibers can be attributed to the characteristic absorption of the $\mathrm{AgCl}$ semiconductor [40], besides, Ag NPs can absorb photons from an area much larger 
1 than their geometric cross section. Resonance energy transfer (RET), the transfer of

2 energy from a plasmon to a nearby semiconductor, enhances the intensity of the

3 electric field thereby increasing optical absorption [41]. In contrast, the increased

4 response in the visible-light region $(400-800 \mathrm{~nm})$ results from the creation of SPR

5 [42]. The significant red shift of the absorption edge observed in the $\mathrm{Ag} / \mathrm{AgCl} @$

6 chiral $\mathrm{TiO}_{2}$ nanofibers (trace c) when compared with $\mathrm{Ag} / \mathrm{AgCl} @$ broken chiral $\mathrm{TiO}_{2}$

7 nanofibers (trace b), demonstrates that controlled chirality at the nanoscale level and

8 the periodic distribution of the plasmonic $\mathrm{Ag} / \mathrm{AgCl}$ in the chiral $\mathrm{TiO}_{2}$ nanofiber,

9 induces a greater SPR effect. The nanostructured ordered helical arrangement of the

$\mathrm{Ag} / \mathrm{AgCl}$ nanoparticles induces coupled plasmon waves propagating along the helical

11 path, causing increased absorption of the incident light components that are in tune

12 with the handedness of the helices. The collective plasmons that oscillate along the

13 plasmonic chiral structure of certain handedness lead to different absorptions in

14 response to right- and left- circularly polarized light [42]. Therefore, the acceleration

15 of SPR excitation results from the nanostructured architecture of ordered and periodically positioned $\mathrm{Ag} / \mathrm{AgCl}$ nanoparticles (Fig. 2), which are irradiated at specific incident polarization angles. Thus, it could be concluded that the more intense

SPR created by $\mathrm{Ag}$ nanoparticles of $\mathrm{Ag} / \mathrm{AgCl} @$ chiral $\mathrm{TiO}_{2}$ nanofibers can cause a stronger local field enhancement around Ag nanoparticles, which can increase light absorption of surrounding dye molecules in a dye-loaded film (Fig. S8, Supplementary Material). The higher rate of light absorption by the dye can result in an enhancement of the rate of electron injection to the photoanode [43]. 
1 The production of energy of the DSPC with the $\mathrm{Ag} / \mathrm{AgCl} @$ chiral $\mathrm{TiO}_{2}$ nanofibers

2 photoanode and with other reference photoanodes were also studied (Fig. S9,

3 Supplementary Material) to exemplify the advantages associated with the use of a

4 chiral plasmonic structure. The PCE values of the cell with $\mathrm{Ag} / \mathrm{AgCl} @$ chiral $\mathrm{TiO}_{2}$

5 nanofibers photoanode were higher than those of reference cell with $\mathrm{Ag} / \mathrm{AgCl} @$

6 broken chiral $\mathrm{TiO}_{2}$ nanofibers, which should be partly attributed to the higher light

7 harvesting efficiency of these materials. Furthermore, in these materials $\mathrm{Ag}$

8 nanoparticles act as an effective 'antenna' for the incident visible light that stores the

9 incident energy and create an intense electromagnetic field in the immediate vicinity

10 [33], which in turn increases the rate of electron-hole formation in some localized

11 regions of the semiconductor by a few orders of magnitude [43]. Concurrently, nanofibers owns faster electron transport, slower recombination rate $[44,45]$ and can serve as light-scattering centers to increase the optical light extinction length in the film, thus also enhancing the light harvesting efficiency [24]. Hence, in the photoanode of this cell, chiral $\mathrm{TiO}_{2}$ nanofibers and $\mathrm{Ag}$ nanoparticles act in a symbiotic relationship that improves the electrical performance of $\mathrm{Ag} / \mathrm{AgCl} @$ chiral $\mathrm{TiO}_{2}$ nanofibers film. Firstly, the SPR effect of Ag nanoparticles is accelerated by the chiral structure due to its capacity of tuning the angle of the incident light and the scattering of light. Secondly, the lifetime of the large amount of electrons generated is extended, owning to the faster electron transport and slower recombination rate in the chiral $\mathrm{TiO}_{2}$ nanofibers. Thirdly, the surface plasmons and light scattering (Ag also acts as a scattering centre) can increase the intensity of the local field and light pathways, 
2 [46]. However, it was unexpected that only slight higher PCE of the cell with

$3 \mathrm{Ag} / \mathrm{AgCl} @$ chiral $\mathrm{TiO}_{2}$ nanofibers than that of pure chiral $\mathrm{TiO}_{2}$ nanofibers was

4 observed (Fig. S9, Supplementary Material). We reason that this is due to the Ag

5 nanoparticles acting as recombination centers, in essence creating internal

6 short-circuits throughout the bulk of the photoactive layer [47]. Hence, the slight PCE

7 improvement should be ascribed to the trade-off between the chiral plasmonic effect

8 and electron recombination role of $\mathrm{Ag}$ nanoparticles.

\subsection{Cell stability and reuse}

The stability and reuse of the DSPC was investigated to establish the effect of inactivation caused by leaching of dye from the photoanode or deposition of by-products. Fig. 7 shows the absorbance of N719 dye deposited on the photoanode as a function of time $t$ relative to the absorbance of a freshly prepared photoanode (i.e., $\left.A_{\mathrm{t}} / A_{0}\right)$ [48]. $45 \%$ of the dye was found to desorb after $24 \mathrm{~h}$ immersion in wastewater, while only $20 \%$ of the dye still remained after $120 \mathrm{~h}$. Therefore, with such long timescale the reduction of photoelectrical performance shown in Fig. 5 cannot be attributed to dye detachment alone.

In general, water is believed to cause a loss of activity in the DSPCs $[49,50]$. For the particular case of $\mathrm{N} 719$ dye, since the redox potential of $\mathrm{ROS} / \mathrm{H}_{2} \mathrm{O}(\sim 2.85 \mathrm{~V} v s . \mathrm{NHE})$ [28] is higher than that of N719/sensitized N719 ( 1.0 V vs. NHE) [33] it is conceivable that the leached dye could be oxidized by ROS after the total 
2 Such effect was demonstrated by examining the photoanode absorbance and

3 photoelectrical performance of the cell with the wastewater sealed in the cell replaced

4 by fresh wastewater every hour or every two hours (referred as $1 \mathrm{~h}$ cell and $2 \mathrm{~h}$ cell).

5 The rate of leached dye (Fig. 7) for the $1 \mathrm{~h}$ cell was as that with the photoanode

7 In contrast, the rate of leached dye for the $2 \mathrm{~h}$ cell was much more rapid, implying

8 N719 molecules were oxidized by the excited ROS after the total removal of TOC.

9 Similarly, the photoelectrical performance of the 1h cell (Fig. 8) showed PCE values of the $1 \mathrm{~h}$ cell decreasing by approximately $50 \%$ (mainly due to the lower $J_{\text {sc }}$ ), and lower $V_{\text {oc }}$ after $24 \mathrm{~h}$, which can be ascribed to dye desorption [20]. However, the loss of photoelectrical performance was significantly higher for the $2 \mathrm{~h}$ cell with a $90 \%$ decrease of the PCE after 12 hours, which should be attributed to the oxidization of N719 after the removal of TOC of the wastewater. Therefore, a more stable performance of the photoanodes can be anticipated if the cell is operated with a continuous flow of fresh wastewater. Further research efforts should be directed towards the production of more stable dyes for use in water-based DSPCs including the use of electrolyte additives (such as ionic surfactants) [51-55] and the use of hydrophobic dye sensitizers [49]. 
2 


\section{4. Conclusion}

2 In summary, a DSPC with $\mathrm{Ag} / \mathrm{AgCl} @$ chiral $\mathrm{TiO}_{2}$ nanofibers as photoanode material,

3 platinized conducting glass as cathode material and actual wastewater as the bridging

4 electrolyte was proposed for simultaneous generation of electricity, hydrogen and

5 contaminants removal. Excellent photoelectrical performance, fast hydrogen

6 generation and contaminants removal were observed due to the symbiotic relationship

7 between Ag nanoparticles and chiral nanofibers, which was exemplified by comparing

8 the photoelectrical performance of $\mathrm{Ag} / \mathrm{AgCl} @$ chiral $\mathrm{TiO}_{2}$ nanofibers photoanode

9 with that of $\mathrm{Ag} / \mathrm{AgCl} @$ broken chiral $\mathrm{TiO}_{2}$ nanofibers. This configuration opens up

10 new opportunities for producing renewable energy from wastewater treatment

11 processes including organic and inorganic matter as viable resources. Chiral

12 nanofibers doped with SPR metal nanoparticles photoanode have great potential in

13 boosting the performance of DSPC. Although the novel DSPC shown here is far from

14 optimum performance, there are huge opportunities for further development. The

15 introduction of a semiconductor insulator could hinder Ag from capturing electrons

16 and the operation of the cell in continuous flow of wastewater may reduce dye

17 leaching. With continued advances in DSPCs for water-based applications, it may

18 therefore be possible to increase the efficiency of energy generation and contaminants

19 removal and finally achieve its successful implementation in domestic and industrial

20 wastewater treatment processes. 


\section{Acknowledgement}

2 The study was financially supported by the National Natural Science Foundation of

3 China (No. 51322901) and the Fundamental Research Funds for the Central

4 Universities (No. 2014B02914), the research fund was provided by the National Basic

5 Research Program of China ('973' program, No. 2010CB429006).

\section{Supplementary Material Available}

7 The characteristics of the wastewater used in this study, detailed photoelectrical

8 performances, XPS, XRD, SEM, UV-vis spectroscopy and EDX results of $\mathrm{Ag} / \mathrm{AgCl}$

$9 @$ chiral $\mathrm{TiO}_{2}$ nanofibers.

\section{References}

[1] P.L. Mcarty, J. Bae, J. Kim, Domestic wastewater treatment as a net energy producer - Can this be achieved? Environ. Sci. Technol. 45 (2011) 7100-7106.

[2] H. Liu, B.E. Logan, Electricity generation using an air-cathode single chamber microbial fuel cell in the presence and absence of a proton exchange membrane. Environ. Sci. Technol. 38 (2004) 4040-4046.

[3] S.K. Chaudhuri, D.R. Lovley, Electricity generation by direct oxidation of glucose in mediatorless microbial fuel cells. Nature Biotechnol. 21 (2003) 1229-1232.

[4] D. Wang, Y. Li, W. Zhang, Q. Wang, C. Wang, P. Wang, Development and modeling of a flat plate serpentine reactor for photocatalytic degradation of 17-ethinylestradiol. Environ, Sci. Poll. Res. 20 (2013) 2321-2329. 
1 [5] M. Narumiya, N. Nakada, N. Yamashita, H. Tanaka, H., Phase distribution and

2 removal of pharmaceuticals and personal care products during anaerobic sludge

3 digestion. J. Hazard. Mater. 260 (2013) 305-312.

4 [6] J. Shen, C. Ou, Z. Zhou, J. Chen, H. Fang, X. Sun, J. Li, L. Zhou, L. Wang,

5 pretreatment of 2,4-dinitroanisole (DNAN) producing wastewater using a combined

6 zero-valent iron (ZVI) reduction and Fenton oxidation process. J. Hazard. Mater. 260

$7 \quad$ (2013) 993-1000.

8 [7] S. Papadimitriou, S. Armyanov, E. Valova, A. Hubin, O. Steenhat, E. Pavlidou, G.

9 Kokkinidis, S. Sotiropoulos, Methanol oxidation at Pt-Cu, Pt-Ni, and Pt-Co electrode coatings prepared by a galvanic replacement process. J. Phys. Chem. C 114 (2010) $5217-5223$.

[8] V.K. Gupta, R. Jain, A. Mittal, T.A. Saleh, A. Nayak, S. Agarwal, S. Sikarwar, Photocatalytic degradation of toxic dye amaranth on $\mathrm{TiO}_{2} / \mathrm{UV}$ in aqueous suspensions. Mater. Sci. Eng.: C 32 (2012) 12-17. 
1 [12] J. Kim, D. Monllor-Satoca, W. Choi, Simultaneous production of hydrogen with

2 the degradation of organic pollutants using $\mathrm{TiO}_{2}$ Photocatalyst modified with dual

3 surface components. Energy Environ. Sci. 5 (2012) 7647-7656.

4 [13] K. Li, Y. Xu, Y. He, C. Yang, Y. Wang, J. Jia, J. Photocatalytic fuel cell (PFC)

5 and dye self-photosensitization photocatalytic fuel cell (DSPFC) with BiOCl/Ti

6 photoanode under UV and visible light irradiation. Environ. Sci. Technol. 47 (2013)

$7 \quad 3490-3497$.

8 [14] W. Zhang, Y. Li, C. Wang, P. Wang, Q. Wang, Energy recovery during

9 advanced wastewater treatment: Simultaneous estrogenic activity removal and hydrogen production through solar photocatalysis. Water Res. 47 (2013) 1480-1490. [15] W. Zhang, Y. Li, C. Wang, P. Wang, Q. Wang, D. Wang, Mechanisms of simultaneous hydrogen production and estrogenic activity removal from secondary effluent through solar photocatalysis. Water Res. 47 (2013) 3173-3182.

[16] P. Lianos, Production of electricity and hydrogen by photocatalytic degradation of organic wastes in a photoelectrochemical cell. The concept of the Photofuelcell: A review of a re-emerging research field. J. Hazard. Mater. 185 (2011) 575-590

[17] E. Stathatos and P. Lianos, S.M. Zakeeruddin, P. Liska, M. Grätzel. A

Quasi-solid-state dye-sensitized solar cell based on a Sol-Gel nanocomposite electrolyte containing ionic liquid. Chem. Mater. 15 (2003) 1825-1829. 
[19] M. Antoniadou and P. Lianos, Production of electricity by photoelectrochemical oxidation of ethanol in a PhotoFuelCell. Appl. Catal. B. Environ. 99 (2010) 307-313.

[20] Z. Ning, Y. Fu, H. Tian, Improvement of dye-sensitized solar cells: What we know and what we need to know. Energy Environ. Sci. 3 (2010) 1170-1181.

[21] F. Hao, P. Dong, Q. Luo, J. Li, J. Lou, H. Lin, Recent advances in alternative cathode materials for iodine-free dye-sensitized solar cell. Energy Environ. Sci. 6 (2013) 2003-2019

[22] D. Wang, Y. Li, G. Li Puma, C. Wang, P. Wang, W. Zhang, Q. Wang, Visible-light driven plasmon photocatalyst $\mathrm{Ag} / \mathrm{AgCl} @$ helical chiral $\mathrm{TiO}_{2}$ nanofibers. Chem. Commun. 49 (2013) 10367-10369.

[23] A. Mills, N. Elliott, G. Hill, D. Fallis, J.R. Durrant, R.L. Willis, Preparation and characterization of novel thick sol-gel titania film photocatalysts. Photochem. Photobiol. Sci. 2 (2003) 591-596.

[24] Y. Bai, H. Yu, Z. Li, R. Amal, G.Q. Lu, L. Wang, In situ growth of a ZnO nanowire network within a $\mathrm{TiO}_{2}$ nanoparticles film for enhanced dye-sensitized solar cells. Advan. Mater. 24 (2012) 5850-5856.

[25] D. Wang, Y. Li, G. Li, C. Wang, W. Zhang, Q. Wang, Modeling of quantitative effects of water components on the photocatalytic degradation of 17 $\alpha$-ethynylestradiol in a modified flat plate serpentine reactor. J. Hazard. Mater. 254-255 (2013) 64-71.

[26] J. Yu, G. Dai, B. Huang, Fabrication and characterization of visible-light driven plasmonic photocatalyst $\mathrm{Ag} / \mathrm{AgCl} / \mathrm{TiO}_{2}$ nanotube arrays. J. Phys. Chem. C 113 (2009) 
2 [27] Y. Tang, Z. Jiang, G. Xing, A. Li, P.D. Kanhere, Y. Zhang, T.C. Sum, S. Li, X.

4 ultrafast plasmon-induced electron transfer processes. Adv. Functional Mater. 23

$5 \quad$ (2013) 2932-2940.

6 [28] T.X. Wu, G.M. Liu, J.C. Zhao, H. Hidaka, N. Serpone, Photoassisted degradation

7 of dye pollutants. V. Self-photosensitized oxidative transformation of rhodamine B

8 under visible light irradiation in aqueous $\mathrm{TiO}_{2}$ dispersions. J. Phys. Chem. B 102 9 (1998) 5845-5851.

[29] C. Hagglund, M. Zach, B. Kasemo, Enhanced charge carrier generation in dye sensitized solar cells by nanoparticles plasmons. Appl. Phys. Lett. 92 (2008) 013113. [30] T. Daeneke, T-H. Kwon, A.B. Holmes, N.W. Duffy, U. Bach, L. Spiccia,

High-efficiency dye-sensitized solar cells with ferrocene-base electrolytes. Nature Chem. 3 (2011) 211-215.

[31] D.T. Scott, D.M. McKnight, E.L. Blunt-Harris, S. E. Kolesar, D.R. Lovely Quinone moieties act as electron acceptors in the reduction of humic substances by humics-reducing microorganisms. Environ. Sci. Technol. 32 (1998) 2984-2989.

[32] J. Lee, H. Park, W. Choi, Selective Photocatalytic oxidation of $\mathrm{NH}_{3}$ to $\mathrm{N}_{2}$ on platinized $\mathrm{TiO}_{2}$ in water. Environ. Sci. Technol. 36 (2002) 5462-5468.

[33] H. Choi, W.T. Chen, P.V. Kamat, Know thy nano neighbor. Plasmonic versus electron charging effects of metal nanoparticles in dye-sensitized solar cell. ACS Nano 6 (2012) 4418-4427. 
1 [34] D. Bui, J. Mu, L. Wang, S. Kang, X. Li, Preparation of Cu-loaded $\mathrm{SrTiO}_{3}$

2 nanoparticles and their photocatalytic activity for hydrogen evolution from methanol

3 aqueous solution. Appl. Surf. Sci. 274 (2013) 328-333.

4 [35] T. Marinado, K. Nonomura, J. Nissfolk, M.K. Karlsson, D.P. Hagberg, L. Sun, S.

5 Mori, A. Hagfeldt, How the nature of triphenylamine-polyene dyes in dye-sensitized

6 solar cells affects the open-circuit voltage and electron lifetimes. Langmuir 26 (2009)

$7 \quad 2592-2598$.

8 [36] B.C. O’Regan, J.R. Durrant. Kinetic and energetic paradigms for dye-sensitized

9 solar cells: moving from the ideal to the real. Accounts of Chem. Res. 42, (2009)

$10 \quad 1799-1808$.

11 [37] B.C. O’Regan, M. Gratzel, Low-cost, High-efficiency solar cell based on dye 12 sensitized colloidal $\mathrm{TiO}_{2}$ films. Nature 24 (1991) 737-740.

[38] H.C. Park, D. Vecitis, W. Choi, O. Weres, M.R. Hoffmann, Solar-powered production of molecular hydrogen from water. J. Phys. Chem. C 112 (2008) 885-889. [39] Dean, J.A., 1998. Lange's handbook of chemistry $15^{\text {th }}$ ed. McGraw-Hill Professional

[40] P. Wang, B. Huang, Z. Lou, X. Zhang, X. Qin, Y. Dai, Z. Zheng, X. Wang, Synthesis of highly efficient $\mathrm{Ag} @ \mathrm{AgCl}$ plasmonic photocatalysts with various structures. Chem.-An European J. 16 (2010) 538-544.

[41] S.C. Warren, E. Thimsen, Plasmonic solar water splitting. Energy Environ. Sci. 5 (2012) 5133-5146.

[42] X. Shen, C. Shen, J. Wang, D. Shi, Z. Wang, N. Liu, B. Ding, Rolling up gold 
nanoparticle-dressed DNA origami into three-dimensional plasmonic chiral nanostructures. J. Am. Chem. Soc. 134 (2012) 146-149.

[43] J. Lee, T. Javed, T. Skeini, A.O. Govorov, G.W. Bryant, N.A. Kotov, Bioconjugated Ag nanoparticles and $\mathrm{CdTe}$ nanowires: Metamaterials with field-enhanced light absorption. Angewandte Chemie Int. Ed. 45 (2006) 4819-4823.

[44] J. Liao, B. Lei, D. Kuang, C. Su, Tri-functional hierarchical $\mathrm{TiO}_{2}$ spheres consisting of anatase nanorods and nanoparticles for high efficiency dye-sensitized solar cells. Energy Environ. Sci. 4 (2011) 4079-4085.

[45] Y. Ohsaki, N. Masaki, T. Kitamura, Y. Wada, T. Okamoto, T. Sekino, K. Niihara, S. Yanagida, Dye-sensitized $\mathrm{TiO}_{2}$ nanotube solar cells: fabrication and electronic characterization. Phys. Chem. Chem. Phys. 7 (2005) 4157-4163.

[46] B. Ding, B.J. Lee, M. Yang, H.S. Jung, J-K. Lee, Surface-plasmon assisted energy conversion in dye-sensitized solar cells. Adv. Energy Mater. 1 (2011) 415-421.

[47] M.D. Brown, T. Suteewong, R.S.S. Kumar, V. d'Innocenzo, A. Petrozza, M.M. Lee, U. Wiesner, H.J. Snaith, Plasmonic dye-sensitized solar cells using core-shell metal-insulator nanoparticles. Nano Lett. 11 (2011) 438-445.

[48] H.J. Son, C. Prasittichai, J.E. Mondloch, L. Luo, J.K.D.W. Wu, O.K., Farha, J.T. Hupp, Dye stabilization and enhanced photoelectrode wettability in water-based dye-sensitized solar cells through post-assembly atomic layer deposition of $\mathrm{TiO}_{2}$. J. Am. Chem. Soc. 135 (2013) 11529-11532.

[49] C. Law, S.C. Pathirana, X. Li, A.Y. Anderson, P.R.F. Barnes, A. Listorti, T.H. Ghaddar, B.C. O’Regan, Water-based electrolytes for dye-sensitized solar cell. Adv. 
1 Mater. 22 (2010) 4505-4509.

2 [50] Y. Liu, Y., A. Hagfeldt, X.R. Xiao, S.E. Lindquist, Investigation of influence of

3 redox species on the interfacial energetics of a dye-sensitized nanoporous $\mathrm{TiO}_{2}$ solar

4 cell. Solar Energy Materials Solar Cells 55 (1998) 267-281.

5 [51] H. Zhang, L. Qiu, X. Dan, W. Zhang, F. Yan, Performance enhancement of water

6 based dye-sensitized solar cells via addition of ionic surfactants. J. Mater. Chem. 2 $7 \quad$ (2014) 2221-2226.

8 [52] T. Daeneke, Y. Uemura, N.W. Duffy, A.J. Mozer, N. Koumura, U. Bach L. 9 Spiccia, Aqueous dye-sensitized solar cell electrolytes based on the ferricyanide-ferrocyanide redox couple. Advan. Mater. 14 (2012) 1222-1225.

[53] Y. Jung, B. Yoo, M.K. Lim, S.Y. Lee, K.J. Kim, Effect of triton-X in water-added electrolytes on the performance of dye-sensitized solar cells. Electrochimica Acta 54 (2009) 6286-6291.

[54] C.Lian, D.Zhi, S. Xu, H. Liu, and Y. Hu. "A lattice model for thermally-sensitive core-shell hydrogels." J. Colloid Interface Sci. 406 (2013) 148-153.

[55] C. Lian, L. Wang, X. Chen, X. Han, S. Zhao, H. Liu, Y. Hu, Modeling Swelling Behavior of Thermoresponsive Polymer Brush with Lattice Density Functional Theory, Langmuir 30 (2014) 4040-4048.

\section{Figure Captions}

Fig. 1. Schematic diagram of the cell. 
1 Fig. 2. Microscopy and schematic drawing of $\mathrm{Ag} / \mathrm{AgCl} @$ chiral $\mathrm{TiO}_{2}$ nanofibers. (A)

2 SEM image of $\mathrm{Ag} / \mathrm{AgCl} @$ chiral $\mathrm{TiO}_{2}$ nanofibers. (B, C) TEM images of $\mathrm{Ag} / \mathrm{AgCl}$

$3 @$ chiral $\mathrm{TiO}_{2}$ nanofibers, which shows there are some nanoparticles deposited on the

4 surfaces of $\mathrm{Ag} / \mathrm{AgCl} @$ chiral $\mathrm{TiO}_{2}$ nanofibers. (D) Structural model showing

$5 \mathrm{Ag} / \mathrm{AgCl}$ nanoparticls deposited on the double helixes. The scale bars in $\mathbf{A}, \mathbf{B}$ and $\mathbf{C}$

6 represent 40,10 and $20 \mathrm{~nm}$, respectively.

7 Fig. 3. SEM image of the photoanode film after deposition by the doctor-blade 8 process and calcination.

9 Fig. 4. The removal of contaminants in the cell. The initial concentrations of TOC,

EE2, DO and TN were $44 \mathrm{mg} / \mathrm{L}, 0.56 \mathrm{mg} / \mathrm{L}, 6.7 \mathrm{mg} / \mathrm{L}$ and $13 \mathrm{mg} / \mathrm{L}$, respectively. The $\mathrm{pH}$ of wastewater was adjusted to 6.0 .

Fig. 5. The electrical performances of the cell: 0 min (black dash trace), 40 min (red dot trace) and $70 \mathrm{~min}$ (blue solid trace). The $\mathrm{pH}$ of wastewater was adjusted to 6.0.

Fig. 6. The accumulation of $\mathrm{H}_{2}$ in the cell ( $\square$ ) and rate of $\mathrm{H}_{2}$ production (O). The $\mathrm{pH}$ of wastewater was adjusted to 6.0.

Fig. 7. Relative $A_{t} / A_{0}$ absorbance of dye molecules (at $510 \mathrm{~nm}$ ) detached from the photoanode immersed in wastewater (-), from the photoanode in the cell with wastewater replaced every hour $(\bullet)$ and every two hours $(\boldsymbol{\bullet})$.

Fig. 8. Time evolution of $\operatorname{PCE}(\mathbf{O}), J_{\mathrm{sc}}(\square)$ and $V_{\mathrm{oc}}(\mathbf{\Delta})$ for the cell with the wastewater was replaced (A) every hour (referred as 1h cell) and (B) every two hours (referred as $2 \mathrm{~h}$ cell). All data were recorded immediately when the wastewater was replaced with fresh wastewater. 


\section{Figures}

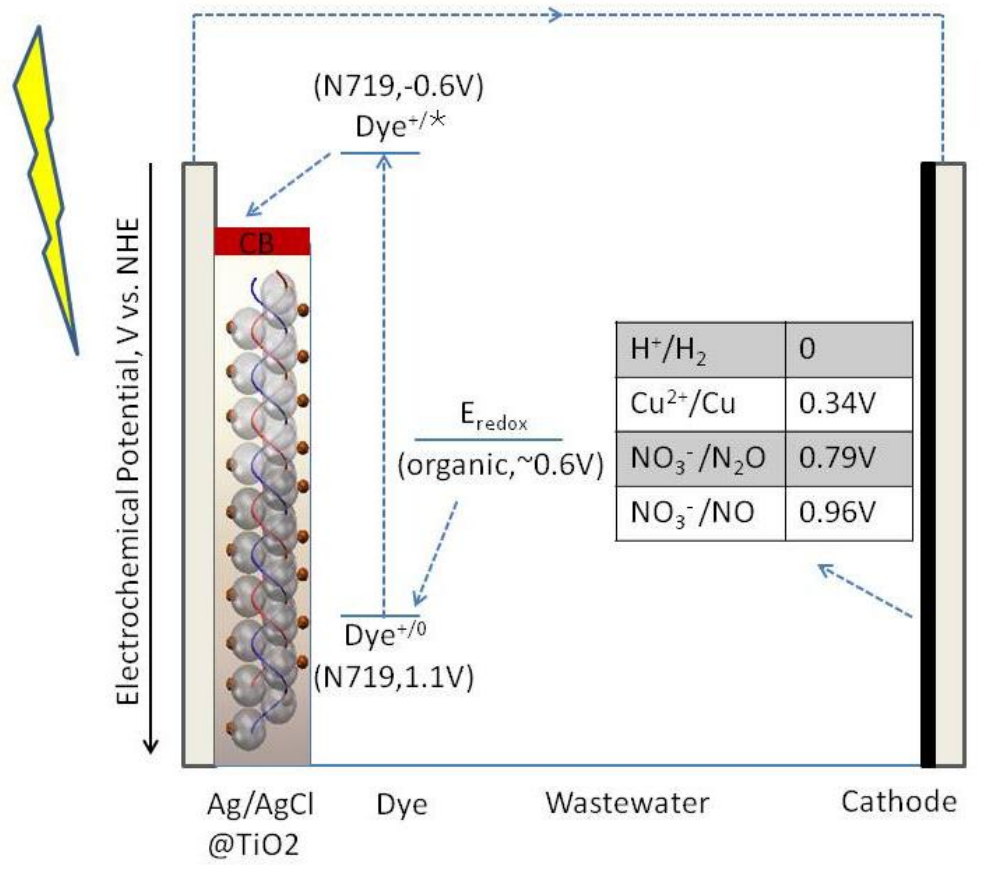

2

3

4

5

6

7

8

9

10

11

12

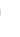

0

12

Fig. 1.

.

.

(

7

8



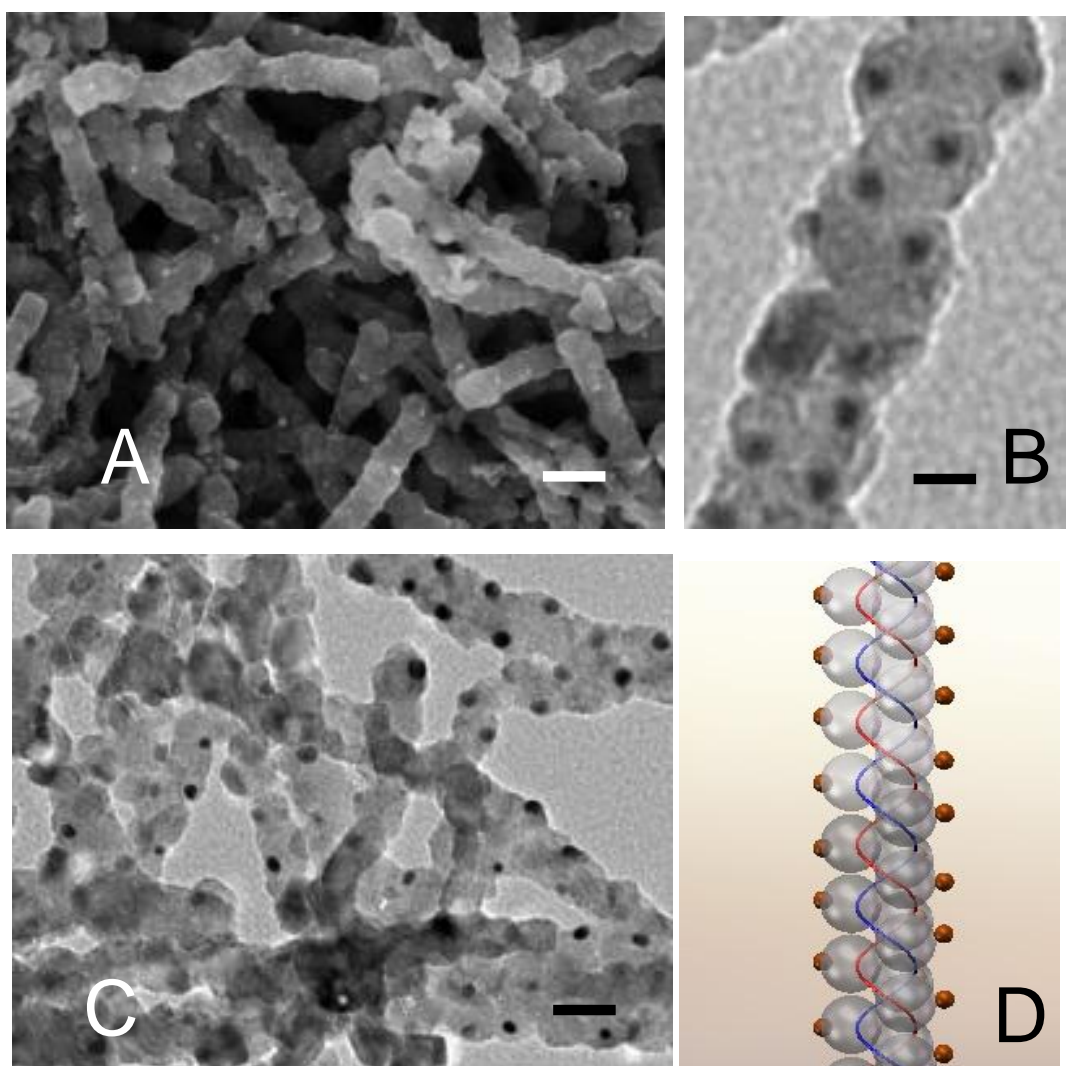

2

3

4

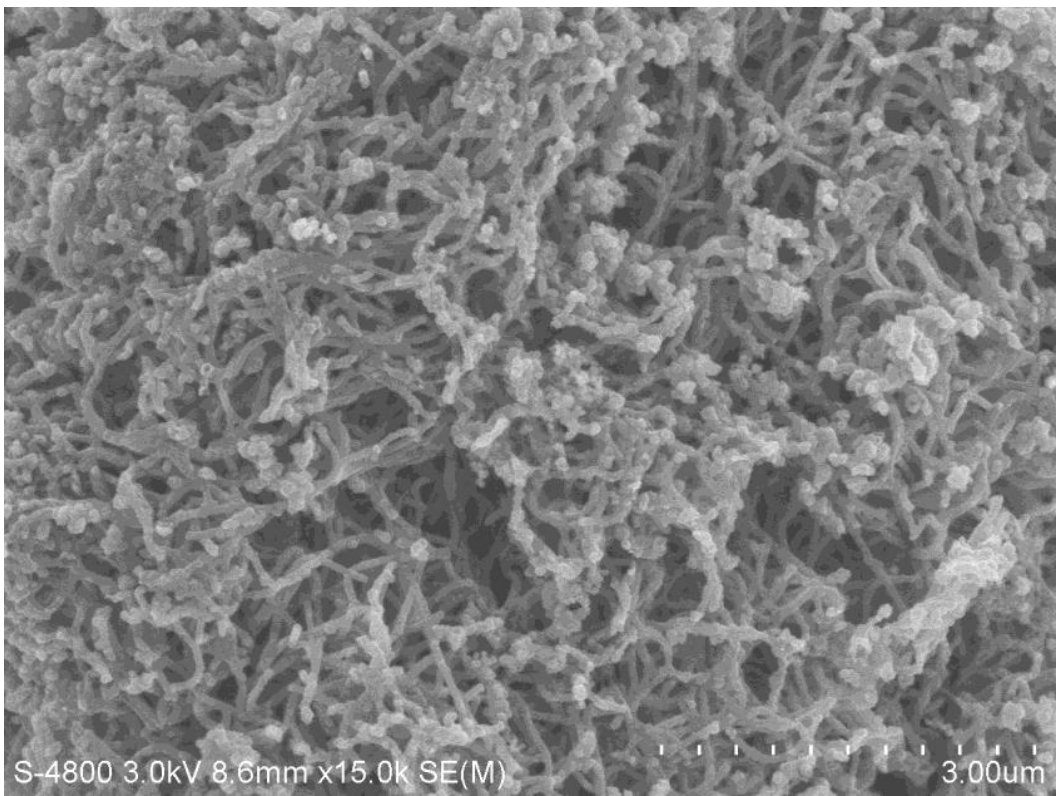

Fig. 3. 


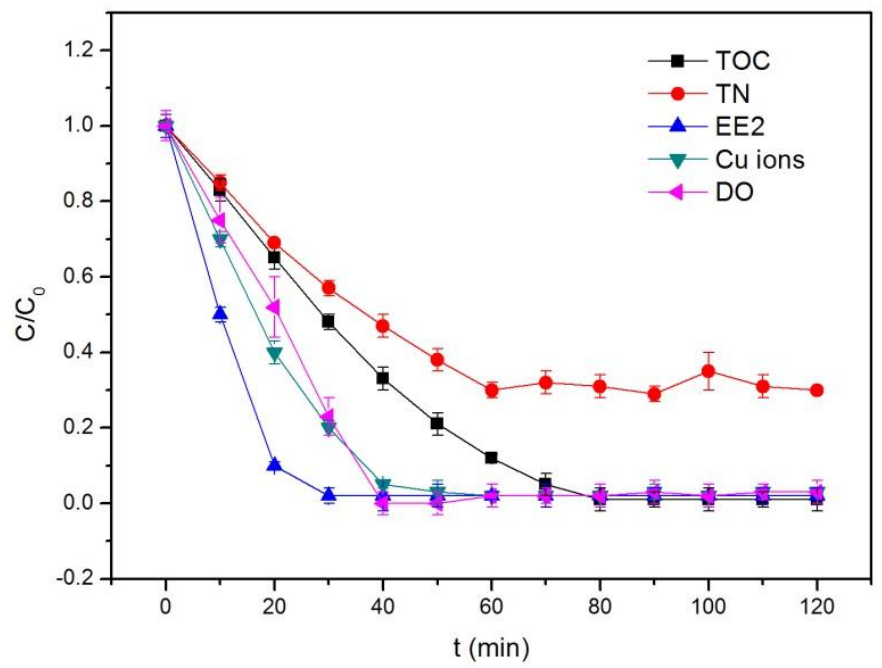

2

3

Fig. 4.

4

5

7

8

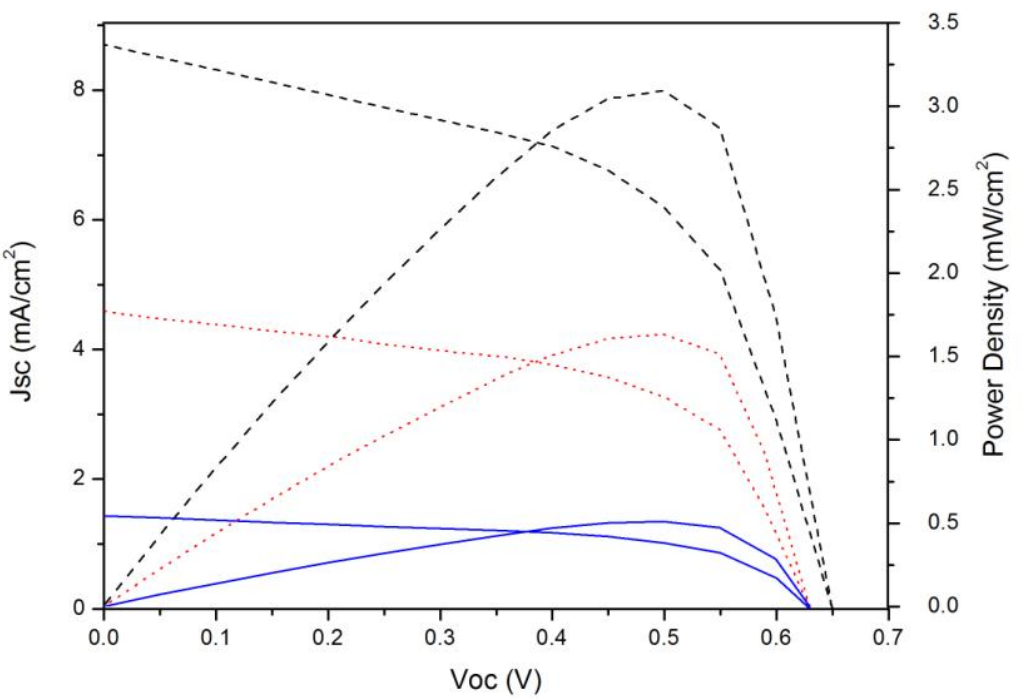

9

Fig. 5.

11 


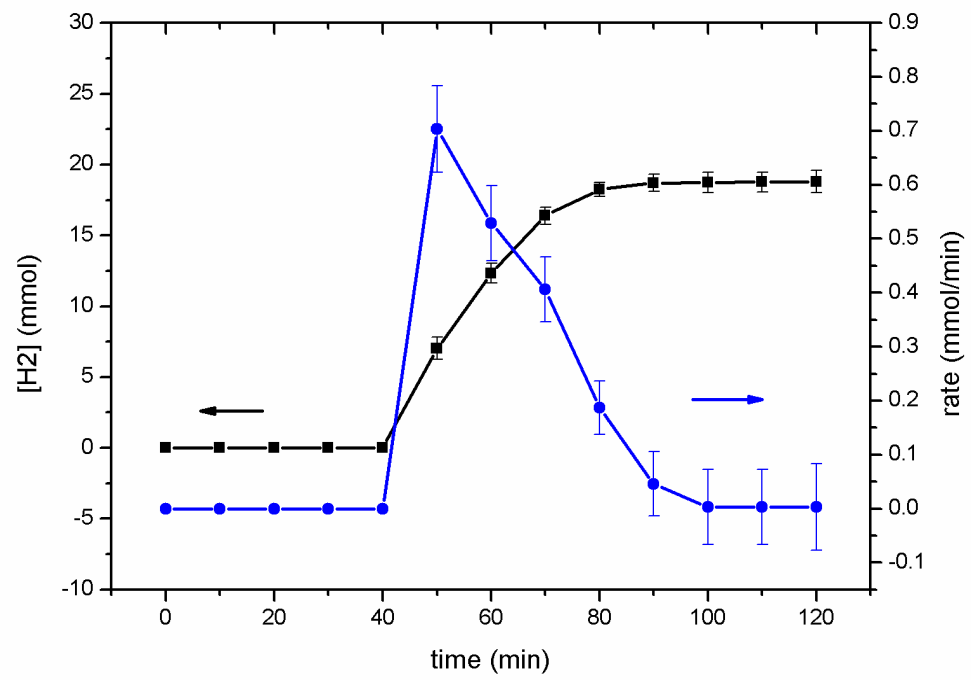

Fig. 6.

2

3

4

5

6

8

9

10

11

12

13

14

15

16

17

18

19

20

21

22

23

24

25

26

27

28

29

30 


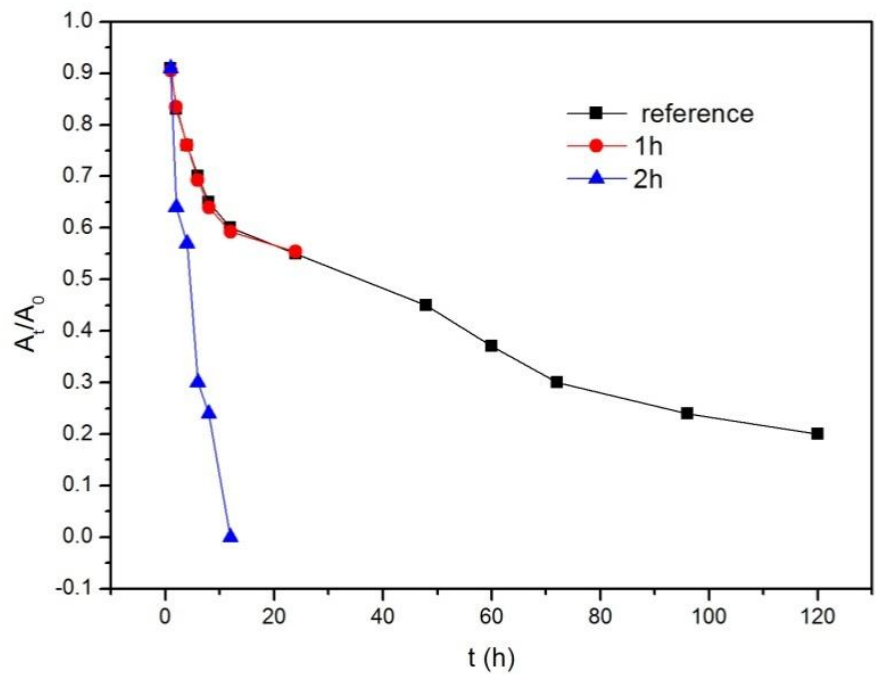

1

Fig. 7.

3

4

5

6

7

8

9 


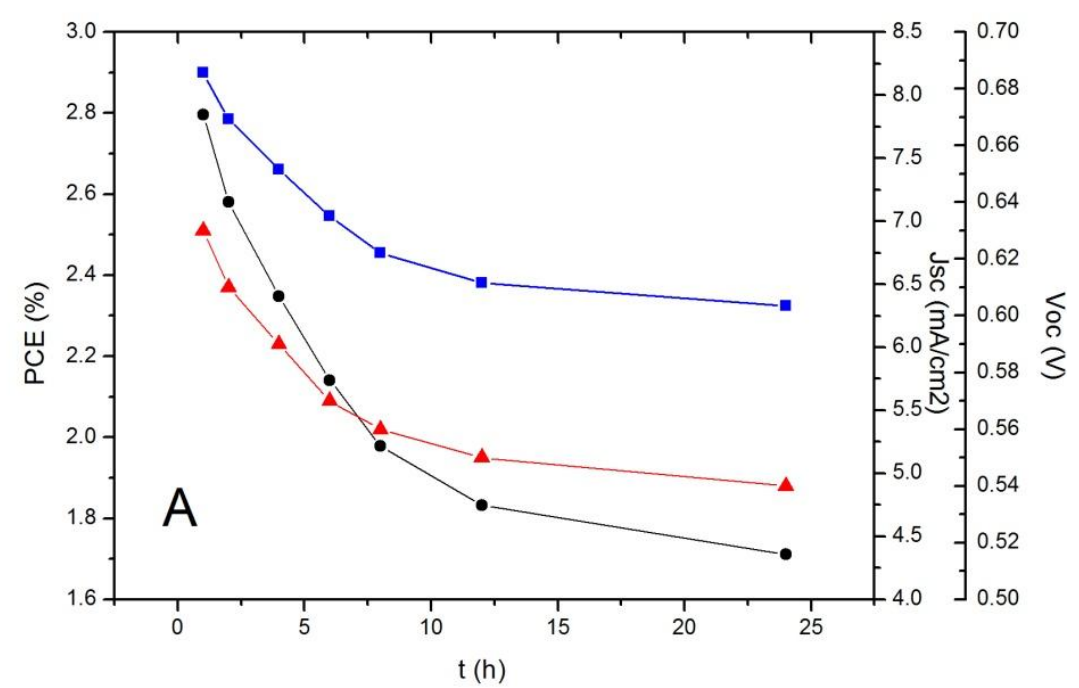

1

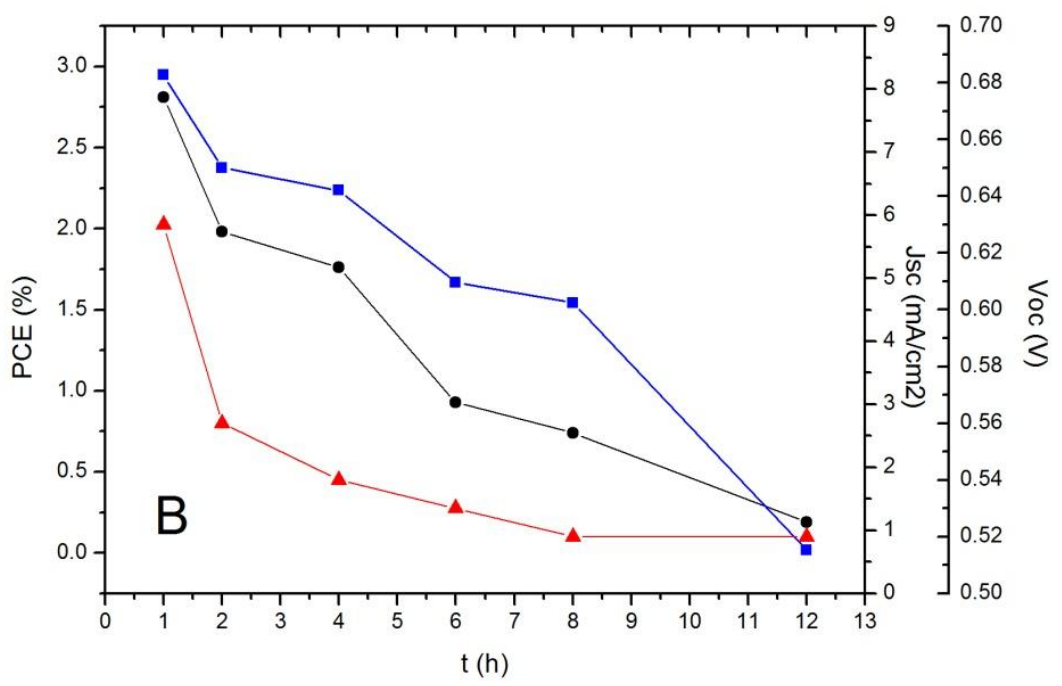

Fig. 8. 


\section{Dye-sensitized solar cells on plasmonic Ag/AgCl @ chiral $\mathrm{TiO}_{2}$ nanofibers for treatment of urban wastewater effluents, with simultaneous production of hydrogen and electricity}

Dawei Wang ${ }^{a}$, Yi $\mathrm{Li}^{a}{ }^{*}$, Gianluca Li Puma ${ }^{b}$, Chao Wang ${ }^{a}$, Peifang Wang ${ }^{a}$, Wenlong Zhang $^{a}$ and Qing Wang ${ }^{a}$

${ }^{a}$ Key Laboratory of Integrated Regulation and Resource Development of Shallow Lakes, Ministry of Education, College of Environment, Hohai University. Xi Kang Road\#1, Nanjing 210098, PR China; E-mail:envly@hhu.edu.cn

${ }^{b}$ Environmental Nanocatalysis \& Photoreaction Engineering, Department of Chemical Engineering, Loughborough University, Loughborough LE11 3TU, United Kingdom;

E-mail: g.lipuma@lboro.ac.uk 


\section{Abstract}

The feasibility of simultaneous production of hydrogen and electricity with simultaneous contaminants removal from "actual" urban wastewater within a dye-sensitized solar cell (DSSC) is demonstrated for the first time. The photoanode in the modified DSSC was a novel nanostructured plasmonic $\mathrm{Ag} / \mathrm{AgCl} @$ chiral $\mathrm{TiO}_{2}$ nanofibers ( $\mathrm{Ag}$ and $\mathrm{AgCl}$ nanoparticles supported on chiral $\mathrm{TiO}_{2}$ nanofibers). The electrolyte in the DSSC was actual wastewater spiked with an estrogen (17- $\beta$-ethynylestradiol, EE2) and a heavy metal $\left(\mathrm{Cu}^{2+}\right)$. The contaminants in the wastewater rather than $\mathrm{I}^{-} / \mathrm{I}_{3}^{-}$(usual electrolyte in conventional DSSCs) acted as electrons bridges for the stabilization of charges in this DSSC. Almost total removal of total organic carbon, $\mathrm{Cu}^{2+}$ and $\mathrm{EE} 2$, and $70 \%$ removal of total nitrogen were achieved under visible-light irradiation. A relatively high solar energy conversion efficiency (PCE 3.09\%) was recorded and approximately $98 \%$ of the electricity was converted to $\mathrm{H}_{2}$ after the consumption of dissolved oxygen, $\mathrm{Cu}^{2+}$ and TN. This performance was attributed to the "symbiotic" relationship between the $\mathrm{TiO}_{2}$ chiral nanofibers and the plasmonic effect of $\mathrm{Ag}$ nanoparticles at the photoanode although $\mathrm{Ag}$ acting as a recombination site may hinder the generation of electricity. This study opens up new opportunities for producing renewable energy from wastewater treatment processes including organic and inorganic matter as viable resources.

\section{Keywords:}

Wastewater treatment, Dye-sensitized solar cell, Hydrogen production, Electricity generation, $\mathrm{Ag} / \mathrm{AgCl} @$ chiral TiO $\mathrm{O}_{2}$ nanofibers 


\section{Introduction}

Energy crisis and increasing environmental pollution are two of the greatest threats to human population sustainability at a global scale. Within this wide contest, wastewater previously considered as a waste is increasingly being used as a valuable resource for producing fresh water, energy and fertilizing nutrients $(\mathrm{N}$ and $\mathrm{P})$. For instance, the wastewater's organic content can be converted into methane gas through the anaerobic process [1], and microbial fuel cell (MFC) [2,3] may also be a viable route for the production of energy from wastewater treatment. Conventional municipal wastewater treatment plants (MWWPs), typically based on biological processes, are unable of removing some emerging contaminants such as endocrine disrupting chemicals [4] pharmaceuticals and personal care products [5]. Furthermore, residual TOC, TN, TP and heavy metals could still remain at the effluent of MWWPs [6]. All these residual contaminants in the effluent represent an increasing threat to human health, the ecological environment and global sustainability, in addition to representing an avoidable loss of valuable energy. Photocatalytic oxidation using $\mathrm{TiO}_{2}$ is an effective method for the removal of these contaminants, it requires no chemicals input or output and $\mathrm{TiO}_{2}$ is inexpensive and non-toxic [7,8]. The photocatalytic oxidation of contaminants is initiated by the excitation of $\mathrm{TiO}_{2}$, which results in the promotion of an electron ( $\left.\mathrm{e}^{-}\right)$from the conduction band $(\mathrm{CB})$ and creation of a hole $\left(\mathrm{h}^{+}\right)$in the valence band (VB) of $\mathrm{TiO}_{2}[9]$. The photogenerated electrons and holes produce highly reactive 
oxygen species (ROS) (i.e. $\mathrm{H}_{2} \mathrm{O}_{2}, \mathrm{HO} \cdot \mathrm{O}_{2}{ }^{-}$) which can attack and oxidize ECs [10], ultimately leading to complete mineralization.

The utilization of freely available solar energy as the only energy input allows photocatalysis to meet the requirements for being a sustainable and green process. However, the most important energy-saving goal in wastewater treatment should be to use a process that can simultaneously capture the chemical energy of the contaminants and that can also meet the effluent quality standards [1]. Although the appeal of the direct conversion of solar into chemical energy during a wastewater treatment process has been recognized for a long time, effective efforts are still scare. Recently, a series of studies have succeeded in using some organic fractions in wastewater (i.e. phenolic compounds and dyes) to act as electron donors for producing $\mathrm{H}_{2}[11,12]$ and for electricity generation [13], and our group has reported the feasibility of hydrogen generation during the removal of emerging contaminants $[14,15]$. Very few studies have focused on the harvesting of energy during the removal of both organic and inorganic compounds (including nutrients and heavy metals etc.) in contaminated water and wastewater, making this the main scientific and technological challenge for the water industry. The recent advances on the development of dye-sensitized solar cells (DSSCs) in recent years may be valuable to address this technological issue.

In a DSSC, the sensitizer, which is usually a dye, absorbs the incident photons resulting in the excitation of electrons from the highest occupied molecular orbital (HOMO) to the lowest unoccupied molecular orbital (LUMO) of the dye. The excited electrons are then injected to the conduction band (CB) of the photoanode material (usually $\mathrm{TiO}_{2}$ ), 
they further transfer to the photoanode fluorine-doped tin oxide (FTO) supporting the $\mathrm{TiO}_{2}$ and through the external load, travel to the cathode FTO and to the cathode material (usually a Pt layer). They then transfer to the HOMO of the redox couples (usually $\mathrm{I}^{-} / \mathrm{I}_{3}{ }^{-}$), and finally back to the HOMO of the dye $[16,17]$ to close the cycle. In this process, the redox couples play a very important role as electrons bridges for the stabilization of charges in the DSSCs. One innovating aspect of the present study is the replacement of the redox couples (such as $\mathrm{I}^{-} / \mathrm{I}_{3}^{-}$) in DSCCs with organic and inorganic compounds naturally occurring in urban wastewater, which collectively can act as an effective electrolyte. The simultaneous production of hydrogen from wastewater may also be achieved according to pioneering works on photoelectrochemical cells [18-21]. Under an ideal situation, organic contaminants may be oxidized by an excited dye in the photoanode, while nitrate and heavy metal could be reduced in the cathode (Fig. 1) including the reduction of protons into $\mathrm{H}_{2}$. Among many aspects the nanostructuring of the photoanode material is key to improving the efficiency of DSSCs.

Our recent study has demonstrated that ordered deposition of $\mathrm{Ag} / \mathrm{AgCl}$ on chiral $\mathrm{TiO}_{2}$ nanofibers enhances the absorption of the incident light in such plasmonic nanostructured composites [22]. One aspect for this enhancement is related to the ability of chiral $\mathrm{TiO}_{2}$ nanofibers to rotate the incident light in a helical pattern [23-26] resulting in the removal of the polarization sensitivity effect of plasmonic materials. This new generation of immobilized plasmonic materials that increases the harvesting of solar light, is incorporated in the photoanode of the DSSC developed in this study which was prepared with plasmonic $\mathrm{Ag} / \mathrm{AgCl} @$ chiral $\mathrm{TiO}_{2}$ nanofibers. 
The modified DSSC with $\mathrm{Ag} / \mathrm{AgCl} @$ chiral $\mathrm{TiO}_{2}$ nanofibers as photoanode material, a platinized FTO sheet as a counter electrode and actual urban wastewater as electrolyte was investigated for the first time for the simultaneous generation of electricity, hydrogen gas and for simultaneous removal of contaminants from wastewater. The performance and the underlying mechanisms of this highly innovating concept for environmental remediation with simultaneous generation of renewable energy are presented in this study.

\section{Materials and Methods}

\subsection{Synthesis of $\mathrm{Ag} / \mathrm{AgCl} @$ chiral $\mathrm{TiO}_{2}$ nanofibers photoanode.}

$\mathrm{C}_{18}$-D-Glu was chosen as template for the synthesis of chiral $\mathrm{TiO}_{2}$ nanofibers [22]. In a typical synthesis, C18-D-Glu (0.06 g, $0.16 \mathrm{mmol})$ was dissolved in a mixture of methanol (27.2 g) and deionized water $(160 \mathrm{ml})$ while stirring at room temperature. After the mixture was stirred for $10 \mathrm{~min}$, TDA $(0.58 \mathrm{~g}, 75 \%$ in isopropanol, purchased from TCI) was added to the mixture with stirring at $55^{\circ} \mathrm{C}$. The mixture was allowed to react at $55{ }^{\circ} \mathrm{C}$ with stirring for $2 \mathrm{~h}$. The products were collected by centrifugal separation and dried by freeze drying at $-60^{\circ} \mathrm{C}$, which resulted in a pale yellow powder. All organics in this product were removed by calcination at $550{ }^{\circ} \mathrm{C}$, and crystalline anatase was obtained. Then, the as-prepared pure chiral $\mathrm{TiO}_{2}$ nanofibers were used to fabricate $\mathrm{Ag} / \mathrm{AgCl} @$ chiral $\mathrm{TiO}_{2}$ nanofibers. In a typical synthesis of $\mathrm{Ag} / \mathrm{AgCl} @$ chiral $\mathrm{TiO}_{2}$ nanofibers, pure chiral $\mathrm{TiO}_{2}$ nanofibers $\left(\begin{array}{ll}0.2 & \mathrm{~g}\end{array}\right)$ and cetyltrimethylammonium chloride $(0.3 \mathrm{~g}$, purchased from $\mathrm{TCI})$ were added into 
deionized water $(100 \mathrm{~mL})$ while stirring at room temperature. After the mixture was stirred for $60 \mathrm{~min}, \mathrm{AgNO}_{3}(2.0 \mathrm{~mL}, 0.1 \mathrm{M})$ was quickly added into the mixture. The resulting solution was stirred at room temperature for further $60 \mathrm{~min}$ and irradiated with an $8 \mathrm{~W}$ UVC light for $40 \mathrm{~min}$. The suspension was collected by centrifugal separation and then dried at $80{ }^{\circ} \mathrm{C}$ for $8 \mathrm{~h}$, which resulted in a brown powder. Finally, the powder was calcined at $300{ }^{\circ} \mathrm{C}$ in air and $\mathrm{Ag} / \mathrm{AgCl} @$ chiral $\mathrm{TiO}_{2}$ nanofibers were obtained. Chiral $\mathrm{TiO}_{2}$ nanofibers were also physically broken with the application of pressure at $10 \mathrm{MPa}$ using FTIR tablet press (to avoid changes of the $\mathrm{TiO}_{2}$ morphological structures) prior to the deposition of $\mathrm{Ag} / \mathrm{AgCl}$, to prepare $\mathrm{Ag} / \mathrm{AgCl} @$ broken chiral $\mathrm{TiO}_{2}$ nanofibers. The synthesis of $\mathrm{Ag} / \mathrm{AgCl} @$ broken chiral $\mathrm{TiO}_{2}$ nanofibers was carried out under the same conditions used to prepare the $\mathrm{Ag} / \mathrm{AgCl} @$ chiral $\mathrm{TiO}_{2}$ nanofibers, to ensure that an equal amount of $\mathrm{Ag} / \mathrm{AgCl}$ was deposited on the same amount of chiral $\mathrm{TiO}_{2}$ nanofibers and broken chiral nanofibers.

\subsection{Assembly of DSSCs.}

The $\mathrm{Ag} / \mathrm{AgCl} @$ chiral $\mathrm{TiO}_{2}$ nanofibers photoanode was prepared by adding $6 \mathrm{~g}$ of PVA (MW 22000, purchased from TCI) into $14 \mathrm{~mL}$ of boiled distilled water with powerful stirring, producing a highly viscous liquid that was further diluted by adding to a solvent made of $18 \mathrm{~mL}$ distilled water and $25 \mathrm{~mL}$ ethanol at $70^{\circ} \mathrm{C}$. Then, $1.62 \mathrm{~g}$ of the as-prepared $\mathrm{Ag} / \mathrm{AgCl} @$ chiral $\mathrm{TiO}_{2}$ nanofibers were added into the PVA/water/ethanol solution to produce a suspension which was then left to cooled to room temperature. The photoanode films were produced on FTO glass $\left(2.3 \mathrm{~mm}\right.$ thickness, $25 \mathrm{~cm}^{2}$ area, 8 $\Omega$ /sq, Dyesol Glass, previously cleaned with 2-propanol in an ultrasonic bath for 30 
min, and then thoroughly rinsed with distilled water, followed by drying on nitrogen) by coating a paste of the suspension using the doctor-blade technique [27]. After coating the films were kept in a clean box for 15 min to relax surface irregularities and the residual mechanical stress of the coating. Finally, the photoanode was gradually heated at $80{ }^{\circ} \mathrm{C}$ for $15 \mathrm{~min}$ and then at $500{ }^{\circ} \mathrm{C}$ for $30 \mathrm{~min}$. The thickness of the film $(11$ $\mu \mathrm{m})$ was increased by repeating this doctor-blade technique [28]. For the preparation of the counter electrode, a drop of $5 \mathrm{mM} \mathrm{H}_{2} \mathrm{PtCl}_{6} \cdot \mathrm{H}_{2} \mathrm{O}$ in 2-propanol was placed on the FTO glass substrate $\left(25 \mathrm{~cm}^{2}\right.$ area), following by drying and annealing at $450{ }^{\circ} \mathrm{C}$ for 30 $\min$.

The photoanode was impregnated with the dye by immersion into a 1:1 (v/v) mixture of acetonitrile (CR, Sigma-Aldrich) and tert-butanol (CR, Sigma-Aldrich) containing a $0.5 \mathrm{mM}$ N719 (Dyesol) dye solution for $6 \mathrm{~h}$. Then, the dye-loaded photoanode was washed with acetonitrile and dried with nitrogen.

The DSSCs were assembled into a sandwich design using the dye loaded photoanode and the cathode. The distance between the two electrodes was $5 \mathrm{~mm}$. The gap between the electrodes was filled with actual wastewater collected from the effluent of a municipal wastewater treatment plant in Suzhou (China) with further addition of 17- $\beta$-ethynylestradiol (EE2) (HPLC grade, Merck) and $\mathrm{CuSO}_{4}$. The chemical properties of the wastewater effluent are presented in Table S1 (SI). The $\mathrm{pH}$ of the wastewater in the DSSCs was adjusted using $1 \mathrm{~mol} / \mathrm{L} \mathrm{H}_{2} \mathrm{SO}_{4}$.

\subsection{Instruments and experimental conditions.}

Scanning electron microscopy (SEM) images were obtained with a JEOL JSM-7041F 
at an accelerating voltage of $1 \mathrm{kV}$. Large scope EDX analysis was conducted on an energy dispersive X-ray spectrometer (ZAF Quantification) attached to the SEM of JEOL JSM-7041F. Transmission electron microscopy (TEM) was performed on a JEOL 2011 operation at $200 \mathrm{kV}$. X-ray diffraction (XRD) patterns were recorded on a Rigaku X-ray diffractometer D/MAX-2200/PC equipped with $\mathrm{Cu} K \alpha$ radiation (40 kV, $20 \mathrm{~mA}$ ). X-ray photoelectron spectroscopy (XPS) results were obtained with PHI 5000C ESCA with $\mathrm{Mg} \mathrm{K \alpha}$ source operating at $14 \mathrm{kV}$ and $25 \mathrm{~mA}$. UV-vis diffuse reflectance spectroscopy was performed in triplicate on similar samples to ensure reproducibility, on a SHIMADZU UV-2450 with a collection speed of $40 \mathrm{~nm} \mathrm{~min}{ }^{-1}$ $\mathrm{BaSO}_{4}$ as the reference. All samples were obtained by scratching films off the FTO substrates and degassing at $200{ }^{\circ} \mathrm{C}$ overnight.

Prior to irradiation, the fabricated DSSC cells were vertically fixed into 12 beakers, each one containing $12.5 \mathrm{~mL}$ of spiked wastewater, and were all shaken in an orbital shaker, in the dark, for $40 \mathrm{~min}$, to establish adsorption-desorption equilibrium of the solution species with the electrodes. Then samples were taken from each beaker, and the beakers were irradiated for two hours using a AM 1.5 solar simulator (Oriel) equipped with a $150 \mathrm{~W}$ xenon light and AM 1.5G type filter (Newport, 81094). samples for analyses were collected at specific time intervals sequentially from each DSSC (one more sample per cell), since the liquid volume in each beaker was small. The current-voltage $(J-V)$ characteristics of the 12 cells were measured as described elsewhere [28]. The amount of hydrogen, the concentrations of EE2, TOC, TN and were measured as shown in our previous studies [4,14,29]. Briefly, the concentration 
of EE2 was detected by High Performance Liquid Chromatography (HPLC, Agilent 1100). TOC was measured by means of a Shimadzu TOC-V VPN with an ANSI-V auto sampler. TN was measured using multi N/C 2100 TOC analyzer (Analytikjena, Germany). DO was monitored with electrode for DO sensor (UC-12-SOL, Central Kagaku Co.). The amount of collected $\mathrm{H}_{2}$ was measured by using a gas chromatograph (HP Agilent, 6890) equipped with a thermal conductivity detector and a molecular sieve 5A column.

\section{Results and Discussion}

\subsection{Characterization of $\mathrm{Ag} / \mathrm{AgCl} @$ chiral $\mathrm{TiO}_{2}$ nanofibers.}

SEM pictures of the $\mathrm{Ag} / \mathrm{AgCl} @$ chiral $\mathrm{TiO}_{2}$ nanofibers (Fig. 2a) revealed that the left-handed, double-helical morphology was preserved after the deposition of the $\mathrm{Ag}$ and $\mathrm{AgCl}$ nanoparticles. The average length of undamaged $\mathrm{TiO}_{2}$ nanofibers was $\sim 500$ $\mathrm{nm}$ and diameter was $\sim 20 \mathrm{~nm}$. TEM analyses (Fig. $2 \mathrm{~b}-\mathrm{c}$ ) revealed that $\mathrm{Ag} / \mathrm{AgCl}$ nanoparticles with the average diameters of 5-8 $\mathrm{nm}$ were deposited on the surface of the chiral $\mathrm{TiO}_{2}$ nanofibers, preferentially at the outer edges of the $\mathrm{TiO}_{2}$ crystals of the helical structure, following the conceptual structure shown in Fig. 2d.

The elemental and chemical compositions of the samples were further determined by XPS. The results (Fig. S1a, SI) suggest that $\mathrm{Ag} / \mathrm{AgCl} @$ chiral $\mathrm{TiO}_{2}$ nanofibers contain $\mathrm{Ti}, \mathrm{O}, \mathrm{C}, \mathrm{Ag}$ and $\mathrm{Cl}$ elements. The $\mathrm{C} 1 \mathrm{~s}$ was attributed to the adventitious hydrocarbon released from the XPS instrument [27]. In Fig. S1b, the Ag 3d spectra consists of two individual peaks approximately at 373 and $367 \mathrm{eV}$, which are due to 
$\operatorname{Ag} 3 d_{3 / 2}$ and $\mathrm{Ag} 3 d_{5 / 2}$ binding energy, respectively. The existence of $\mathrm{Ag}^{0}$ and $\mathrm{Ag}^{+1}$ could be verified by further peaks divisions [28]. Consequently, the XPS analyses suggested that the nanoparticles deposited on chiral $\mathrm{TiO}_{2}$ nanofibers were made of $\mathrm{Ag} / \mathrm{AgCl}$ composites. The elemental composition determined by EDX (Fig. S2), resulted in a $\mathrm{Ag}$ content of $5.49 \mathrm{~mol} \%$ and a $\mathrm{Cl}$ content of $2.86 \mathrm{~mol} \%$, which indicated that the $\mathrm{Ag} / \mathrm{AgCl}$ was virtually at a $1: 1$ molar ratio. $\mathrm{XRD}$ results also suggested the co-existence of $\mathrm{Ag}$ and $\mathrm{AgCl}$ (Fig. S3 and detailed descriptions in SI). Further details on material characterization have been reported [22].

\subsection{Contaminants removal in the DSSC.}

EE2 representing for chemically stable organic compounds and $\mathrm{Cu}^{2+}$ representing for heavy metal ions were spiked into the wastewater at specific concentrations to investigate the removal of contaminants (TOC, TN, EE2 and $\mathrm{Cu}^{2+}$ ) in the cell (Fig. 3). TOC, EE2 and $\mathrm{Cu}^{2+}$ were totally removed after $80 \mathrm{~min}, 80 \mathrm{~min}$ and $55 \mathrm{~min}$ respectively, while only approximately $70 \%$ of $\mathrm{TN}$ was removed within $120 \mathrm{~min}$. Meanwhile, a decrease of DO over time was observed, indicating the mineralization of TOC and EE2 is aerobic [15]. The fast photodegradation of the TOC including EE2 should be attributed to the combined effect of (i) the strong photocatalytic activity of irradiated $\mathrm{Ag} / \mathrm{AgCl} @$ chiral $\mathrm{TiO}_{2}$ nanofibers and of (ii) the oxidization ability of sensitized dyes. Regarding the first effect, $\mathrm{Ag} / \mathrm{AgCl} @$ chiral $\mathrm{TiO}_{2}$ nanofibers under visible-light irradiation produces photogenerated electron-hole pairs in the $\mathrm{Ag}$ nanoparticles due to surface plasmon resonance (SPR) [30]. In this process, SPR generates the electron-hole pairs in the semiconductor $\left(\mathrm{AgCl}\right.$ and $\left.\mathrm{TiO}_{2}\right)$ by the 
dipole-dipole interaction between the donor $(\mathrm{Ag})$ and the acceptors $\left(\mathrm{AgCl}\right.$ and $\left.\mathrm{TiO}_{2}\right)$. The photocatalytic activity of $\mathrm{Ag} / \mathrm{AgCl} @$ chiral $\mathrm{TiO}_{2}$ nanofibers should mainly be attributed to two simultaneous processes. The strong electronic coupling between $\mathrm{Ag}$ and $\mathrm{AgCl}$ conduction bands which injects photoinduced electrons from the $\mathrm{Ag}$ nanoparticles, quickly and efficiently, into the $\mathrm{AgCl}[31]$ and into the $\mathrm{TiO}_{2}$ helical structure, yielding superoxide radicals and finally HO radicals from the reductive pathway [32]. However, this effect seems negligible for the removal of the contaminants since the direct charge transfer from noble nanoparticles (Hagglund et al., 2008) or the internal photoemission from $\mathrm{TiO}_{2}$ and $\mathrm{AgCl}$ [33] only play a supporting role in the photoelectrical performance. This was verified of the $J-V$ characteristics of the solar cells not sensitized with dye N719 (see Fig S4).

Regarding the effect of the sensitized dye on the removal of TOC and EE2, the redox potential of N719/sensitized N719 is $1.0 \mathrm{~V}$ ( $v s$. normal hydrogen electrode (NHE)) [17] which is sufficient to oxidize most organic compounds in wastewater, since their redox potentials were mostly less than $0.6 \mathrm{~V} v s$. NHE [35] As a result, the reduction of the sensitized dye to its ground state maintained the cell cycle until all organic contaminants were removed from the wastewater. Since the synthesized wastewater was acid, the decrease in the $\mathrm{TN}$ should be attributed to the reduction of $\mathrm{NO}_{3}{ }^{-}$by the electrons transferred to the photocathode:

$$
\begin{aligned}
& \mathrm{NO}_{3}^{-}+2 \mathrm{H}^{+}+\mathrm{e}^{-} \rightarrow \mathrm{N}_{2} \mathrm{O}+\mathrm{H}_{2} \mathrm{O} \quad \mathrm{E}^{0}=0.7989 \mathrm{~V} \\
& \mathrm{NO}_{3}^{-}+4 \mathrm{H}^{+}+3 \mathrm{e}^{-} \rightarrow \mathrm{NO}+\mathrm{H}_{2} \mathrm{O} \quad \mathrm{E}^{0}=0.9637 \mathrm{~V}
\end{aligned}
$$

This significant mass deficit in the $\mathrm{TN}$ balance also confirms some gaseous product 
such as $\mathrm{NO}$ and $\mathrm{N}_{2} \mathrm{O}$ are generated as a result of $\mathrm{NO}_{3}{ }^{-}$reduction. The $30 \%$ of $\mathrm{TN}$ survived from the photoelectrical degradation should be $\mathrm{NH}_{3}-\mathrm{N}$ as they cannot be reduced in acid or neutral conditions [36].

3.3. Photoelectrical performance and hydrogen generation of the DSSC.

SPR is characterized by a build-up of intense, spatially non-homogeneous oscillating electric fields in the neighbourhood of the nanostructure [22]. The SPR effect at the photoanode improves the efficiency of the DSSCs by (1) increased light absorption due to surface plasmons and light-trapping effects, (2) improved charge separation as a result of the localized electro-magnetic field, (3) the promotion of electron transfer to adsorbed species, and (4) the electron storage effect that can shifts the Fermi level to more negative potentials [37-40]. Although the direct charge transfer from $\mathrm{Ag}$ nanoparticles to the semiconductor may also prove useful for the electricity generation as mentioned above, the main mechanism of photo-excitation of the photoanode with visible light implies the sensitization of the N719 dye, and the transfer of excited electrons to the $\mathrm{Ag} / \mathrm{AgCl} @$ chiral $\mathrm{TiO}_{2}$ nanofibers, the external load, the counter cathode and lastly the simultaneous reductions of $\mathrm{NO}_{3}{ }^{-}, \mathrm{H}^{+}$and of $\mathrm{Cu}^{2+}$. The presence of metallic $\mathrm{Cu}$ on the surface of the counter electrode after the process was further substantiated by two XPS peaks at $932.6 \mathrm{eV}$ and $952.5 \mathrm{eV}$ [38-41] (Fig. S5.). In parallel to the above mechanism, the sensitized N719 dye is reduced back to its ground state by the adsorbed organic matter and nitrogen, which were present in the wastewater, therefore, sacrificial organic and inorganic matter are essential to sustain the mechanism of the DSSCs. This mechanism is further 
exemplified by the current-voltage $(J-V)$ and current-power densities $(J-P)$ plots, which were recorded to investigate the electrical performance of the cell (Fig. 4).

The short-circuit current densities $\left(J_{s c}\right)$, open-circuit voltage $\left(V_{o c}\right)$ and power densities varied with time during the irradiation of DSSCs. $J_{s c}$ decreased significantly over time and it even turned to be $0.02 \mathrm{~mA} / \mathrm{cm}^{2}$ after $80 \mathrm{~min}$ and then remained stable, while $V_{o c}$ just showed slight decrease (Table S2). These should be attributed to the removal of contaminants in the cell as they functioned as electrons bridges. Moreover, $J_{s c}$ is determined by electron injection [16,39] which depends on the concentration of contaminants, hence, $J_{s c}$ decreased eventually to a relatively low level as the contaminants were totally removed, after $80 \mathrm{~min}$. However, $J_{s c}$ did not decrease to 0 as expected, this may be due to $\mathrm{Ag}$ can also be excited by visible-light irradiation while $\mathrm{TiO}_{2}$ can be excited by the small fraction of UV accessible under AM 1.5 irradiation, and also produced electron-hole pairs [37]. Then the produced electrons transferred through external load to counter photocathode while the holes may react with $\mathrm{H}_{2} \mathrm{O}$. This is consistent with the photoelectrical performances of the solar cells not sensitized with N719 (Fig. S4). Meanwhile, these produced holes may also oxidize some N719 molecules and disable this DSSC (this will be discussed in following section). In contrast, $V_{o c}$ is largely affected by the properties of the photoanode, i.e., the conductive band potential of the photoanode and the dye absorption number [40], thus $V_{o c}$ decreased. The fill factors (Table 1) were calculated according to [41]:

$$
f f=\frac{P_{\max }}{J_{s c} V_{o c}}
$$


where $P_{\max }$ is the maximum power density.

Fig. 5 shows the photogeneration of $\mathrm{H}_{2}$ over time in the DSSCs. The electrons transferred to the counter electrodes reduced protons to $\mathrm{H}_{2}$, although some $\mathrm{H}_{2}$ could also be formed during the degradation of organic matter [11, 42]. The $\mathrm{H}_{2}$ production was not observed until 40 min $c a$., when DO and $\mathrm{Cu}^{2+}$ were almost totally consumed (Fig. 3) as the redox potentials of $\mathrm{Cu}^{2+} / \mathrm{Cu}\left(0.3394 \mathrm{~V} v\right.$. NHE) and $\mathrm{O}_{2} / \mathrm{H}_{2} \mathrm{O}(1.229 \mathrm{~V}$ vs. NHE) were higher than that of $\mathrm{H}^{+} / \mathrm{H}_{2}(0 \mathrm{vs}$. NHE) [43]. In agreement with the electrical performance, the rate of $\mathrm{H}_{2}$ production gradually decreased as the concentration of contaminants decreased and reached approximately zero, after 80 min, when the electricity was only generated due to the excitation of $\mathrm{TiO}_{2}$ and $\mathrm{Ag}$ under irradiation.

The photo-electricity conversion efficiency (PCE) was calculated (Table S2) to evaluate the photoelectrical performance of DSSC. An efficiency of 3.09\% was recorded at $0 \mathrm{~min}$, indicating $3.09 \%$ of the incident light energy was converted into electricity. Moreover, the electricity-hydrogen conversion efficiency (ECE) was calculated:

$$
\operatorname{ECE}(\%)=\frac{E_{\mathrm{H}_{2}}}{E_{\mathrm{el}}}=\frac{2 n_{t} U}{\int P_{\max } A d t} \times 100
$$

where $E_{\mathrm{H}_{2}}$ is the $\mathrm{H}_{2}$ energy $(\mathrm{J})$ produced by the cell, $E_{\mathrm{el}}$ is generated electricity energy on the photoanode $(\mathrm{J}), P_{\max }$ is the maximum power density $\left(\mathrm{W} / \mathrm{cm}^{2}\right), A$ is the irradiated surface area of photoanode $\left(\mathrm{cm}^{2}\right), n$ is the total amount of hydrogen produced (mol), $U$ is the hydrogen energy content $(122 \mathrm{~kJ} / \mathrm{g}$ ) and $t$ is time (s). As shown in Table S2, $78.1 \%$ of the electricity generated from 40 to 50 min was 
converted to hydrogen energy. While after $60 \mathrm{~min}$, approximately $98 \%$ of the electricity was converted due to the total removal of $\mathrm{Cu}^{2+}$ and $\mathrm{NO}_{3}{ }^{-}$in the wastewater.

\subsection{Chirality and plasmonic effect in the DSSC.}

The highest PCE in this study was $3.09 \%$ which is relatively high considering the electrolyte was actual wastewater rather than $\mathrm{I}^{-} / \mathrm{I}_{3}{ }^{-}$solution. This supports the superior performance of $\mathrm{Ag} / \mathrm{AgCl} @$ chiral $\mathrm{TiO}_{2}$ nanofibers as photoanode in the DSSC. Herein, the photoanodes prepared with chiral $\mathrm{TiO}_{2}$ nanofibers, $\mathrm{Ag} / \mathrm{AgCl} @$ broken chiral $\mathrm{TiO}_{2}$ nanofibers served as references, to exemplify the chiral plasmonic effect on the performance of the DSSC. The SEM and TEM pictures of these reference photoanode are shown in Fig. S6. The absorption spectrums of $\mathrm{Ag} / \mathrm{AgCl} @$ chiral $\mathrm{TiO}_{2}$ nanofibers thin film and other reference photoanode thin films are shown in Fig. S7. The stronger absorption of $\mathrm{Ag} / \mathrm{AgCl} @$ chiral $\mathrm{TiO}_{2}$ nanofibers at 200-350 nm compared to pure chiral $\mathrm{TiO}_{2}$ nanofibers can be attributed to the characteristic absorption of the $\mathrm{AgCl}$ semiconductor [44], besides, $\mathrm{Ag}$ NPs can absorb photons from an area much larger than their geometric cross section. Resonance energy transfer (RET, the transfer of energy from a plasmon to a nearby semiconductor) enhances the electric field intensity thereby increasing the optical absorption [45]. In contrast, the increased response in the visible-light region $(400-800 \mathrm{~nm})$ results from the creation of SPR [46]. The significant red shift of the absorption edge observed in the $\mathrm{Ag} / \mathrm{AgCl}$ @ chiral $\mathrm{TiO}_{2}$ nanofibers (trace c) when compared with $\mathrm{Ag} / \mathrm{AgCl} @$ broken chiral $\mathrm{TiO}_{2}$ nanofibers (trace b), demonstrates that controlled chirality at the nanoscale level induces a greater SPR effect. The nanostructured ordered helical arrangement of the 
$\mathrm{Ag} / \mathrm{AgCl}$ nanoparticles induces coupled plasmon waves propagating along the helical path, causing increased absorption of the incident light components that are in tune with the handedness of the helices. The collective plasmons that oscillate along the plasmonic chiral structure of certain handedness lead to different absorptions in response to right- and left- circularly polarized light [46]. Therefore, the acceleration of SPR excitation results from the nanostructured architecture of ordered $\mathrm{Ag} / \mathrm{AgCl}$ nanoparticles, which are irradiated at specific incident polarization angles. Thus, it could be concluded that the more intense SPR created by Ag nanoparticles of $\mathrm{Ag} / \mathrm{AgCl} @$ chiral $\mathrm{TiO}_{2}$ nanofibers can cause a stronger local field enhancement around Ag nanoparticles, which can increase light absorption of surrounding dye molecules in a dye-loaded film (Fig. S7). The higher rate of light absorption by the dye can result in an enhancement of the rate of electron injection to the photoanode [47].

The production of energy of the $\mathrm{DSSC}$ with the $\mathrm{Ag} / \mathrm{AgCl} @$ chiral $\mathrm{TiO}_{2}$ nanofibers photoanode and with other reference photoanodes were also studied (Fig. S8) to exemplify the advantages associated with the use of a chiral plasmonic structure. The PCE values of the cell with $\mathrm{Ag} / \mathrm{AgCl} @$ chiral $\mathrm{TiO}_{2}$ nanofibers photoanode were higher than those of reference cell with $\mathrm{Ag} / \mathrm{AgCl} @$ broken chiral $\mathrm{TiO}_{2}$ nanofibers, which should be partly attributed to the higher light harvesting efficiency of these materials. Furthermore, in these materials Ag nanoparticles act as an effective 'antenna' for the incident visible light that stores the incident energy and create an intense electromagnetic field in the immediate vicinity [23, 37], which in turn 
increases the rate of electron-hole formation in some localized regions of the semiconductor by a few orders of magnitude [47]. Concurrently, nanofibers owns faster electron transport, slower recombination rate [48,49] and can serve as light-scattering centers to increase the optical length in the film, thus also enhancing the light harvesting efficiency [28]. Hence, in the photoanode of this cell, chiral $\mathrm{TiO}_{2}$ nanofibers and $\mathrm{Ag}$ nanoparticles act in a symbiotic relationship that improves the electrical performance of $\mathrm{Ag} / \mathrm{AgCl} @$ chiral $\mathrm{TiO}_{2}$ nanofibers film. Firstly, the SPR effect of $\mathrm{Ag}$ nanoparticles is accelerated by the chiral structure due to its capacity of tuning the angle of the incident light and the scattering of light. Secondly, the lifetime of the large amount of electrons generated is extended, owning to the faster electron transport and slower recombination rate in the chiral $\mathrm{TiO}_{2}$ nanofibers. However, it was unexpected that only slight higher PCE of the cell with $\mathrm{Ag} / \mathrm{AgCl} @$ chiral $\mathrm{TiO}_{2}$ nanofibers than that of pure chiral $\mathrm{TiO}_{2}$ nanofibers was observed (Fig. S4). We reason that this is due to the Ag nanoparticles acting as recombination centers, in essence creating internal short-circuits throughout the bulk of the photoactive layer [50]. Hence, the slight PCE improvement should be ascribed to the trade-off between the chiral plasmonic effect and electron recombination role of Ag nanoparticles.

\subsection{Cell stability and reuse.}

The stability and reuse of the DSSC was investigated to establish the effect of inactivation caused by leaching of dye from the photoanode or deposition of by-products. Fig. 6 shows the absorbance of N719 dye deposited on the photoanode as a function of time $t$ relative to the absorbance of a freshly prepared photoanode (i.e., 
$\left.A_{\mathrm{t}} / A_{0}\right)$ [51]. $45 \%$ of the dye was found to desorb after $24 \mathrm{~h}$ immersion in wastewater, while only $20 \%$ of the dye still remained after $120 \mathrm{~h}$. Therefore, with such long timescale the reduction of photoelectrical performance shown in Fig. 4 cannot be attributed to dye detachment alone.

In general, water is believed to cause a loss of activity in the DSSCs [52, 53]. For the particular case of $\mathrm{N} 719$ dye, since the redox potential of $\mathrm{ROS} / \mathrm{H}_{2} \mathrm{O}(\sim 2.85 \mathrm{~V}$ vs. NHE) [32] is higher than that of N719/sensitized N719 ( 1.0 V vs. NHE) [37] it is conceivable that the leached dye could be oxidized by ROS after the total consumption of TOC from the wastewater.

Such effect was demonstrated by examining the photoanode absorbance and photoelectrical performance of the cell with the wastewater sealed in the cell replaced by fresh wastewater every hour or every two hours (referred as $1 \mathrm{~h}$ cell and $2 \mathrm{~h}$ cell). The rate of leached dye (Fig. 6) for the $1 \mathrm{~h}$ cell was as that with the photoanode soaked in wastewater since the TOC of the wastewater was never totally consumed. In contrast, the rate of leached dye for the $2 \mathrm{~h}$ cell was much more rapid, implying N719 molecules were oxidized by the excited ROS after the total removal of TOC.

Similarly, the photoelectrical performance of the $1 \mathrm{~h}$ cell (Fig. 7) showed PCE values of the $1 \mathrm{~h}$ cell decreasing by approximately $50 \%$ (mainly due to the lower $J_{\mathrm{sc}}$ ), and lower $V_{\text {oc }}$ after $24 \mathrm{~h}$, which can be ascribed to dye desorption [16]. However, the loss of photoelectrical performance was significantly higher for the $2 \mathrm{~h}$ cell with a $90 \%$ decrease of the PCE after 12 hours, which should be attributed to the oxidization of N719 after the removal of TOC of the wastewater. Therefore, a more stable 
performance of the photoanodes can be anticipated if the cell is operated with a continuous flow of fresh wastewater. Further research efforts should be directed towards the production of more stable dyes for use in water-based DSSCs including the use of electrolyte additives (such as ionic surfactants) [54-56] and the use of hydrophobic dye sensitizers [52]. 


\section{Conclusion}

In summary, a modified DSSC with $\mathrm{Ag} / \mathrm{AgCl} @$ chiral $\mathrm{TiO}_{2}$ nanofibers as photoanode material, platinized conducting glass as cathode material and actual wastewater as the bridging electrolyte was proposed for simultaneous generation of electricity, hydrogen and contaminants removal. Excellent photoelectrical performance, fast hydrogen generation and contaminants removal were observed due to the symbiotic relationship between Ag nanoparticles and chiral nanofibers, which was exemplified by comparing the photoelectrical performance of $\mathrm{Ag} / \mathrm{AgCl} @$ chiral $\mathrm{TiO}_{2}$ nanofibers photoanode with that of $\mathrm{Ag} / \mathrm{AgCl} @$ broken chiral $\mathrm{TiO}_{2}$ nanofibers. This configuration opens up new opportunities for producing renewable energy from wastewater treatment processes including organic and inorganic matter as viable resources. Chiral nanofibers doped with SPR metal nanoparticles photoanode have great potential in boosting the performance of DSSCs. Although the novel DSSC shown here is far from optimum performance, there are huge opportunities for further development. The introduction of a semiconductor insulator could hinder Ag from capturing electrons and the operation of the cell in continuous flow of wastewater may reduce dye leaching. With continued advances in DSSCs for water-based applications, it may therefore be possible to increase the efficiency of energy generation, metal recycling and contaminants removal and finally achieve its successful implementation in domestic and industrial wastewater treatment processes. 


\section{Acknowledgement}

The study was financially supported by the National Natural Science Foundation of China (No. 51322901) and the Fundamental Research Funds for the Central Universities (No. 2014B02914), the research fund was provided by the National Basic Research Program of China ('973’ program, No. 2010CB429006).

\section{Supporting Information Available}

The characteristics of the wastewater used in this study, detailed photoelectrical performances, XPS, XRD and $\mathrm{EDX}$ results of $\mathrm{Ag} / \mathrm{AgCl} @$ chiral $\mathrm{TiO}_{2}$ nanofibers.

\section{References}

[1] P.L. Mcarty, J. Bae, J. Kim, Domestic wastewater treatment as a net energy producer - Can this be achieved? Environ. Sci. Technol. 45 (2011) 7100-7106.

[2] H. Liu, B.E. Logan, Electricity generation using an air-cathode single chamber microbial fuel cell in the presence and absence of a proton exchange membrane. Environ. Sci. Technol. 38 (2004) 4040-4046.

[3] S.K. Chaudhuri, D.R. Lovley, Electricity generation by direct oxidation of glucose in mediatorless microbial fuel cells. Nature Biotechnol. 21 (2003) 1229-1232.

[4] D. Wang, Y. Li, W. Zhang, Q. Wang, C. Wang, P. Wang, Development and modeling of a flat plate serpentine reactor for photocatalytic degradation of 17-ethinylestradiol. Environ, Sci. Poll. Res. 20 (2013) 2321-2329.

[5] M. Narumiya, N. Nakada, N. Yamashita, H. Tanaka, H., Phase distribution and 
removal of pharmaceuticals and personal care products during anaerobic sludge digestion. J. Hazard. Mater. 260 (2013) 305-312.

[6] J. Shen, C. Ou, Z. Zhou, J. Chen, H. Fang, X. Sun, J. Li, L. Zhou, L. Wang, pretreatment of 2,4-dinitroanisole (DNAN) producing wastewater using a combined zero-valent iron (ZVI) reduction and Fenton oxidation process. J. Hazard. Mater. 260 (2013) 993-1000.

[7] S. Papadimitriou, S. Armyanov, E. Valova, A. Hubin, O. Steenhat, E. Pavlidou, G. Kokkinidis, S. Sotiropoulos, Methanol oxidation at Pt-Cu, Pt-Ni, and Pt-Co electrode coatings prepared by a galvanic replacement process. J. Phys. Chem. C 114 (2010) $5217-5223$

[8] V.K. Gupta, R. Jain, A. Mittal, T.A. Saleh, A. Nayak, S. Agarwal, S. Sikarwar, Photocatalytic degradation of toxic dye amaranth on $\mathrm{TiO}_{2} / \mathrm{UV}$ in aqueous suspensions. Mater. Sci. Eng.: C 32 (2012) 12-17.

[9] D.M.A. Alrousan, M.I. Polo-Lopez, P.S.M., Dunlop, P. Fernandez-Ibanez, J.A. Byrne, Solar photocatalytic disinfection of water with immobilised titanium dioxide in re-circulating flow CPC reactors. Appl. Catal. B: Environ. 128 (2012) 126-134.

[10] M.N. Chong, B. Jin, C.W.K. Chow, C. Saint, Recent development in photocatalytic water treatment technology: A review. Water Res. 44 (2010) 2997-3027.

[11] J. Kim, W. Choi, W. Hydrogen producing water treatment through solar photocatalysis. Energy Environ. Sci. 3 (2010) 1042-1045.

[12] J. Kim, D. Monllor-Satoca, W. Choi, Simultaneous production of hydrogen with 
the degradation of organic pollutants using $\mathrm{TiO}_{2}$ Photocatalyst modified with dual surface components. Energy Environ. Sci. 5 (2012) 7647-7656.

[13] K. Li, Y. Xu, Y. He, C. Yang, Y. Wang, J. Jia, J. Photocatalytic fuel cell (PFC) and dye self-photosensitization photocatalytic fuel cell (DSPFC) with $\mathrm{BiOCl} / \mathrm{Ti}$ photoanode under UV and visible light irradiation. Environ. Sci. Technol. 47 (2013) 3490-3497.

[14] W. Zhang, Y. Li, C. Wang, P. Wang, Q. Wang, Energy recovery during advanced wastewater treatment: Simultaneous estrogenic activity removal and hydrogen production through solar photocatalysis. Water Res. 47 (2013) 1480-1490.

[15] W. Zhang, Y. Li, C. Wang, P. Wang, Q. Wang, D. Wang, Mechanisms of simultaneous hydrogen production and estrogenic activity removal from secondary effluent through solar photocatalysis. Water Res. 47 (2013) 3173-3182.

[16] Z. Ning, Y. Fu, H. Tian, Improvement of dye-sensitized solar cells: What we know and what we need to know. Energy Environ. Sci. 3 (2010) 1170-1181.

[17] F. Hao, P. Dong, Q. Luo, J. Li, J. Lou, H. Lin, Recent advances in alternative cathode materials for iodine-free dye-sensitized solar cell. Energy Environ. Sci. 6 (2013) 2003-2019

[18] S.K. Mohapatra, M. Misra, V.K. Mahajan, K.S. Raja, Design of a highly efficient photoelectrolytic cell for hydrogen generation by water splitting: application of $\mathrm{TiO}_{2-x} \mathrm{C}_{x}$ nanotubes as a photoanode and $\mathrm{Pt} / \mathrm{TiO}_{2}$ nanotubes as a cathode. J. Phys. Chem. C 111 (2007) 8677-8685.

[19] N. Kondamudi, M. Misra, M., Banerjee, S. Subarna., S. Mohapatra, S., 
Mohapatra, Simultaneous production of glyceric acid and hydrogen from the photooxidation of crude glycerol using $\mathrm{TiSi}_{2}$. Appl. Catal. B: Environ. 126 (2012) $180-185$.

[20] Z. Liu, B. Pesic, K.S. Raja, R.R. Rangaraju, M. Misra, Hydrogen generation under sunlight by self ordered $\mathrm{TiO}_{2}$ nanotube arrays. Int. J. Hydrogen Energy 34 (2009) 3250-3257.

[21] M. Antoniadou, P. Bouras, N. Strataki, P. Lianos, Hydrogen and electricity generation by photoelectrochemical decomposition of ethanol over nanocrystalline titania. Int. J. Hydrogen Energy 33 (2008) 5045-5051.

[22] D. Wang, Y. Li, G. Li Puma, C. Wang, P. Wang, W. Zhang, Q. Wang, Visible-light driven plasmon photocatalyst $\mathrm{Ag} / \mathrm{AgCl} @$ helical chiral $\mathrm{TiO}_{2}$ nanofibers. Chem. Commun. 49 (2013) 10367-10369.

[23] H.A. Atwater, A. Polman, A., Plasmonics for improved photovoltaic devices. Nature Mater. 9 (2010) 205-213.

[24] S.A. Maier, Plasmonics-Fundamentals and Applications; Springer: New York, 2007.

[25] K.E. Shopsowitz, H. Qi, W.Y. Hamad, M.J. Maclachlan, Free-standing mesoporous silica films with tunable chiral nematic structures. Nature 468 (2010) $422-425$.

[26] J. Xie, S. Che, Chirality of anisotropic metal nanowires with distinct multihelix. Chemistry-An European J. 18 (2012) 15954-15959.

[27] A. Mills, N. Elliott, G. Hill, D. Fallis, J.R. Durrant, R.L. Willis, Preparation and 
characterization of novel thick sol-gel titania film photocatalysts. Photochem. Photobiol. Sci. 2 (2003) 591-596.

[28] Y. Bai, H. Yu, Z. Li, R. Amal, G.Q. Lu, L. Wang, In situ growth of a ZnO nanowire network within a $\mathrm{TiO}_{2}$ nanoparticles film for enhanced dye-sensitized solar cells. Advan. Mater. 24 (2012) 5850-5856.

[29] Wang, D., Li, Y., Li, G., Wang, C., Zhang, W., Wang, Q., 2013c. Modeling of Quantitative Effects of Water Components on the Photocatalytic Degradation of 17 a-ethynylestradiol in A Modified Flat Plate Serpentine Reactor. Journal of Hazardous Materials 254-255, 64-71.

[30] J. Yu, G. Dai, B. Huang, Fabrication and characterization of visible-light driven plasmonic photocatalyst $\mathrm{Ag} / \mathrm{AgCl} / \mathrm{TiO}_{2}$ nanotube arrays. J. Phys. Chem. C 113 (2009) 16394-16401.

[31] Y. Tang, Z. Jiang, G. Xing, A. Li, P.D. Kanhere, Y. Zhang, T.C. Sum, S. Li, X. Chen, Z. Dong, Z. Chen, Efficient Ag@ AgCl cubic cage photocatalysts profit from ultrafast plasmon-induced electron transfer processes. Adv. Functional Mater. 23 (2013) 2932-2940.

[32] T.X. Wu, G.M. Liu, J.C. Zhao, H. Hidaka, N. Serpone, Photoassisted degradation of dye pollutants. V. Self-photosensitized oxidative transformation of rhodamine B under visible light irradiation in aqueous $\mathrm{TiO}_{2}$ dispersions. J. Phys. Chem. B 102 (1998) 5845-5851 .

[33] C. Hagglund, M. Zach, B. Kasemo, Enhanced charge carrier generation in dye sensitized solar cells by nanoparticles plasmons. Appl. Phys. Lett. 92 (2008) 013113 
[34] K. Ishikawa, C-J. Wen, K. Yamada, T. Okubo, The photocurrent of dye-sensitized solar cells enhanced by the surface plasmon resonance. J. Chem. Eng. Japan. 37 (2004) 645-649.

[35] D.T. Scott, D.M. McKnight, E.L. Blunt-Harris, S. E. Kolesar, D.R. Lovely Quinone moieties act as electron acceptors in the reduction of humic substances by humics-reducing microorganisms. Environ. Sci. Technol. 32 (1998) 2984-2989.

[36] J. Lee, H. Park, W. Choi, Selective Photocatalytic oxidation of $\mathrm{NH}_{3}$ to $\mathrm{N}_{2}$ on platinized $\mathrm{TiO}_{2}$ in water. Environ. Sci. Technol. 36 (2002) 5462-5468.

[37] H. Choi, W.T. Chen, P.V. Kamat, Know thy nano neighbor. Plasmonic versus electron charging effects of metal nanoparticles in dye-sensitized solar cell. ACS Nano 6 (2012) 4418-4427.

[38] D. Bui, J. Mu, L. Wang, S. Kang, X. Li, Preparation of Cu-loaded $\mathrm{SrTiO}_{3}$ nanoparticles and their photocatalytic activity for hydrogen evolution from methanol aqueous solution. Appl. Surf. Sci. 274 (2013) 328-333.

[39] T. Marinado, K. Nonomura, J. Nissfolk, M.K. Karlsson, D.P. Hagberg, L. Sun, S. Mori, A. Hagfeldt, How the nature of triphenylamine-polyene dyes in dye-sensitized solar cells affects the open-circuit voltage and electron lifetimes. Langmuir 26 (2009) 2592-2598.

[40] B.C. O’Regan, J.R. Durrant. Kinetic and energetic paradigms for dye-sensitized solar cells: moving from the ideal to the real. Accounts of Chem. Res. 42, (2009) 1799-1808.

[41] B.C. O’Regan, M.A. Gratzel, Low-cost, High-efficiency solar cell based on dye 
sensitized colloidal $\mathrm{TiO}_{2}$ films. Nature 24 (1991) 737-740.

[42] H.C. Park, D. Vecitis, W. Choi, O. Weres, M.R. Hoffmann, Solar-powered production of molecular hydrogen from water. J. Phys. Chem. C 112 (2008) 885-889.

[43] Dean, J.A., 1998. Lange's handbook of chemistry $15^{\text {th }}$ ed. McGraw-Hill Professional

[44] P. Wang, B. Huang, Z. Lou, X. Zhang, X. Qin, Y. Dai, Z. Zheng, X. Wang, Synthesis of highly efficient $\mathrm{Ag} @ \mathrm{AgCl}$ plasmonic photocatalysts with various structures. Chem.-An European J. 16 (2010) 538-544.

[45] S.C. Warren, E. Thimsen, Plasmonic solar water splitting. Energy Environ. Sci. 5 (2012) 5133-5146.

[46] X. Shen, C. Shen, J. Wang, D. Shi, Z. Wang, N. Liu, B. Ding, Rolling up gold nanoparticle-dressed DNA origami into three-dimensional plasmonic chiral nanostructures. J. Am. Chem. Soc. 134 (2012) 146-149.

[47] J. Lee, T. Javed, T. Skeini, A.O. Govorov, G.W. Bryant, N.A. Kotov, Bioconjugated Ag nanoparticles and CdTe nanowires: Metamaterials with field-enhanced light absorption. Angewandte Chemie Int. Ed. 45 (2006) 4819-4823.

[48] J. Liao, B. Lei, D. Kuang, C. Su, Tri-functional hierarchical $\mathrm{TiO}_{2}$ spheres consisting of anatase nanorods and nanoparticles for high efficiency dye-sensitized solar cells. Energy Environ. Sci. 4 (2011) 4079-4085.

[49] Y. Ohsaki, N. Masaki, T. Kitamura, Y. Wada, T. Okamoto, T. Sekino, K. Niihara, S. Yanagida, Dye-sensitized $\mathrm{TiO}_{2}$ nanotube solar cells: fabrication and electronic characterization. Phys. Chem. Chem. Phys. 7 (2005) 4157-4163. 
[50] M.D. Brown, T. Suteewong, R.S.S. Kumar, V. d'Innocenzo, A. Petrozza, M.M. Lee, U. Wiesner, H.J. Snaith, Plasmonic dye-sensitized solar cells using core-shell metal-insulator nanoparticles. Nano Lett. 11 (2011) 438-445.

[51] H.J. Son, C. Prasittichai, J.E. Mondloch, L. Luo, J.K.D.W. Wu, O.K., Farha, J.T. Hupp, Dye stabilization and enhanced photoelectrode wettability in water-based dye-sensitized solar cells through post-assembly atomic layer deposition of $\mathrm{TiO}_{2}$. J. Am. Chem. Soc. 135 (2013) 11529-11532.

[52] C. Law, S.C. Pathirana, X. Li, A.Y. Anderson, P.R.F. Barnes, A. Listorti, T.H. Ghaddar, B.C. O’Regan, Water-based electrolytes for dye-sensitized solar cell. Adv. Mater. 22 (2010) 4505-4509.

[53] Y. Liu, Y., A. Hagfeldt, X.R. Xiao, S.E. Lindquist, Investigation of influence of redox species on the interfacial energetics of a dye-sensitized nanoporous $\mathrm{TiO}_{2}$ solar cell. Solar Energy Materials Solar Cells 55 (1998) 267-281.

[54] H. Zhang, L. Qiu, X. Dan, W. Zhang, F. Yan, Performance enhancement of water based dye-sensitized solar cells via addition of ionic surfactants. J. Mater. Chem. 2 (2014) 2221-2226.

[55] T. Daeneke, Y. Uemura, N.W. Duffy, A.J. Mozer, N. Koumura, U. Bach L. Spiccia, Aqueous dye-sensitized solar cell electrolytes based on the ferricyanide-ferrocyanide redox couple. Advan. Mater. 14 (2012) 1222-1225.

[56] Y. Jung, B. Yoo, M.K. Lim, S.Y. Lee, K.J. Kim, Effect of triton-X in water-added electrolytes on the performance of dye-sensitized solar cells. Electrochimica Acta 54 (2009) 6286-6291. 


\section{Figure Captions}

Fig. 1. Schematic diagram of the cell.

Fig. 2. Microscopy and schematic drawing of $\mathrm{Ag} / \mathrm{AgCl} @$ chiral $\mathrm{TiO}_{2}$ nanofibers. (A) SEM image of $\mathrm{Ag} / \mathrm{AgCl} @$ chiral $\mathrm{TiO}_{2}$ nanofibers. (B, C) TEM images of $\mathrm{Ag} / \mathrm{AgCl}$ @ chiral $\mathrm{TiO}_{2}$ nanofibers, which shows there are some nanoparticles deposited on the surfaces of $\mathrm{Ag} / \mathrm{AgCl} @$ chiral $\mathrm{TiO}_{2}$ nanofibers. (D) Structural model showing $\mathrm{Ag} / \mathrm{AgCl}$ nanoparticls deposited on the double helixes. The scale bars in $\mathbf{A}, \mathbf{B}$ and $\mathbf{C}$ represent 40, 10 and $20 \mathrm{~nm}$, respectively.

Fig.3. The removal of contaminants in the cell. The initial concentrations of TOC, EE2, DO, $\mathrm{Cu}^{2+}$ and TN were $44 \mathrm{mg} / \mathrm{L}, 0.56 \mathrm{mg} / \mathrm{L}, 6.7 \mathrm{mg} / \mathrm{L}, 1.03 \mathrm{mg} / \mathrm{L}$ and $13 \mathrm{mg} / \mathrm{L}$, respectively. The $\mathrm{pH}$ of wastewater was adjusted to 6.0 .

Fig. 4. The electrical performances of the cell: 0 min (black dot trace), $40 \mathrm{~min}$ (red solid trace) and $70 \mathrm{~min}$ (blue dash trace). The $\mathrm{pH}$ of wastewater was adjusted to 6.0.

Fig. 5. The accumulation of $\mathrm{H}_{2}$ in the cell ( $\left.\boldsymbol{\square}\right)$ and rate of $\mathrm{H}_{2}$ production (O). The $\mathrm{pH}$ of wastewater was adjusted to 6.0 .

Fig. 6. (A) UV-vis absorption spectrums of (a) Pure chiral $\mathrm{TiO}_{2}$ nanofibers. (b) $\mathrm{Ag} / \mathrm{AgCl} @$ broken chiral $\mathrm{TiO}_{2}$ nanofibers. (c) $\mathrm{Ag} / \mathrm{AgCl} @$ chiral $\mathrm{TiO}_{2}$ nanofibers. (B) Corresponding spectra of the dye adsorbed onto the photoanode films.

Fig. 7. Time evolution of $\operatorname{PCE}(\mathbf{O}), J_{\mathrm{sc}}(\square)$ and $V_{\mathrm{oc}}(\mathbf{\Delta})$ for the cell with the wastewater was replaced (A) every hour (referred as 1h cell) and (B) every two hours (referred as $2 \mathrm{~h}$ cell). All data were recorded immediately when the wastewater was replaced with fresh wastewater. 
Figures

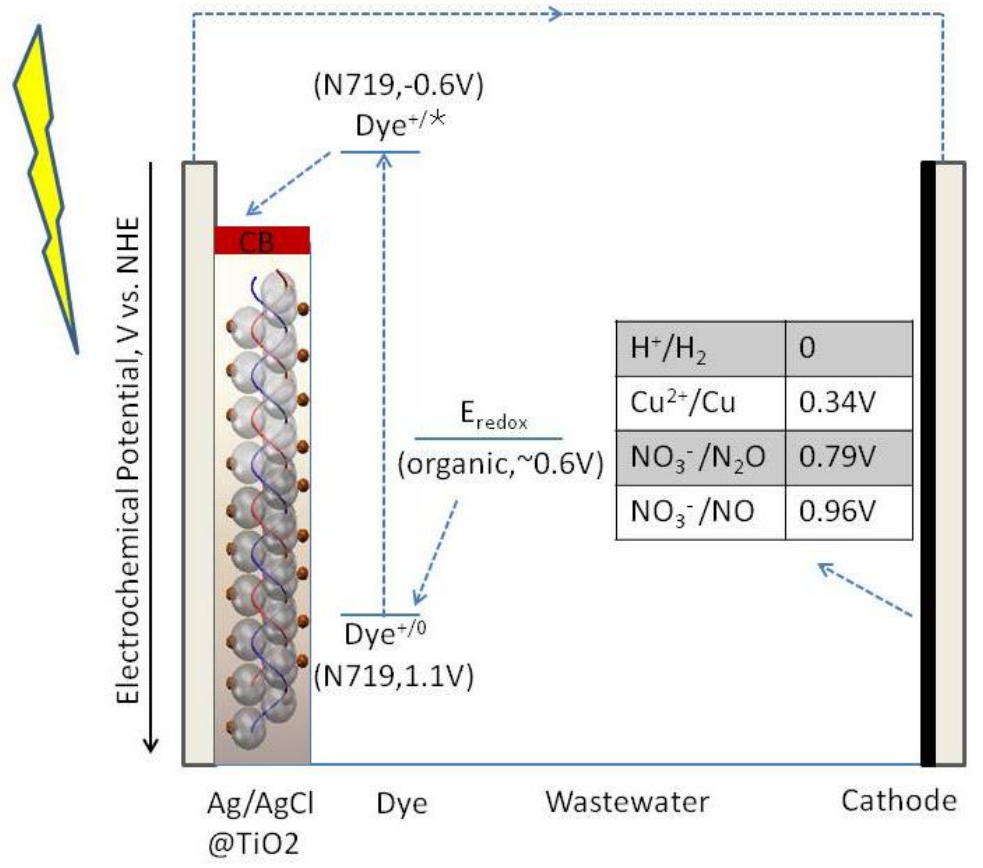

Fig. 1. 

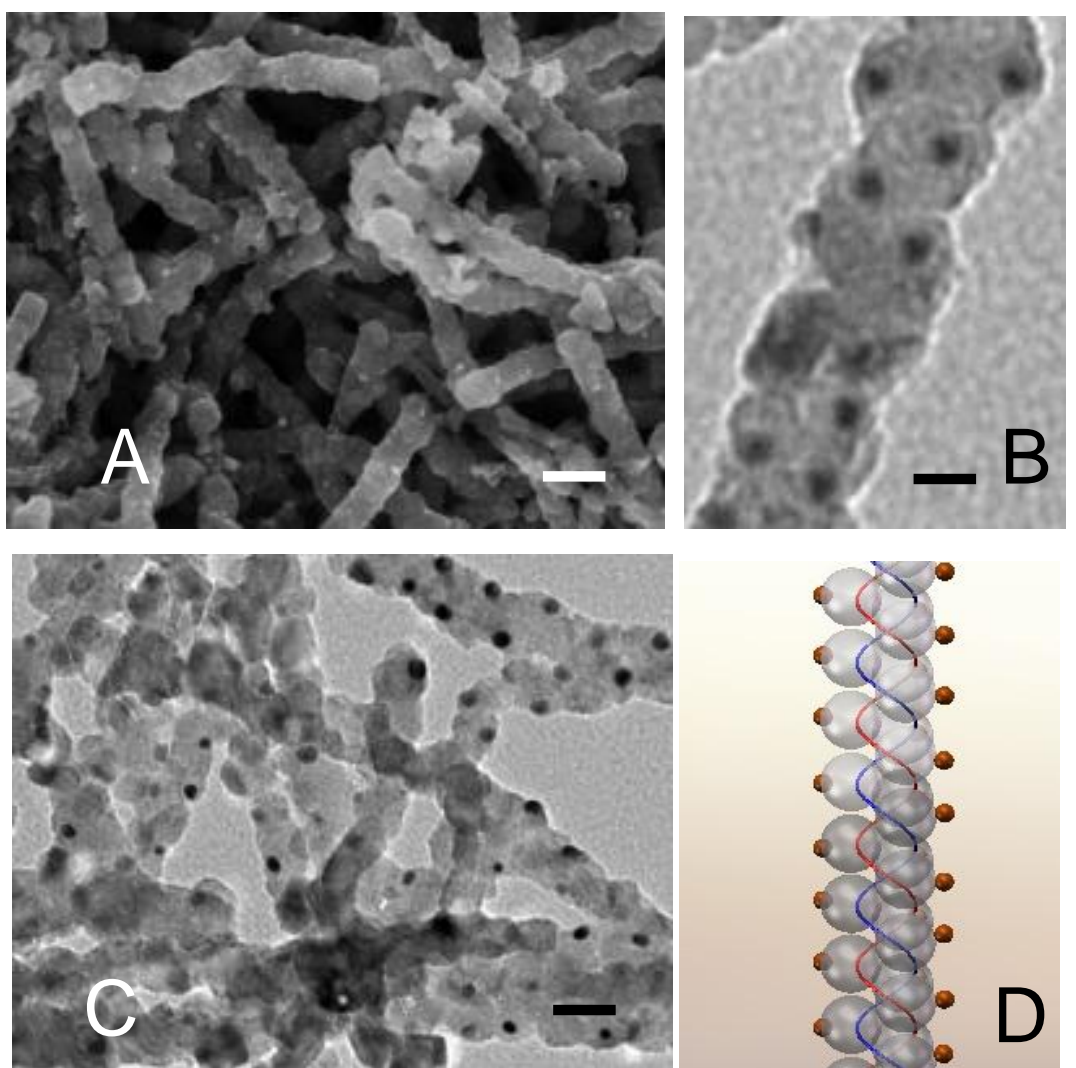

Fig. 2. 


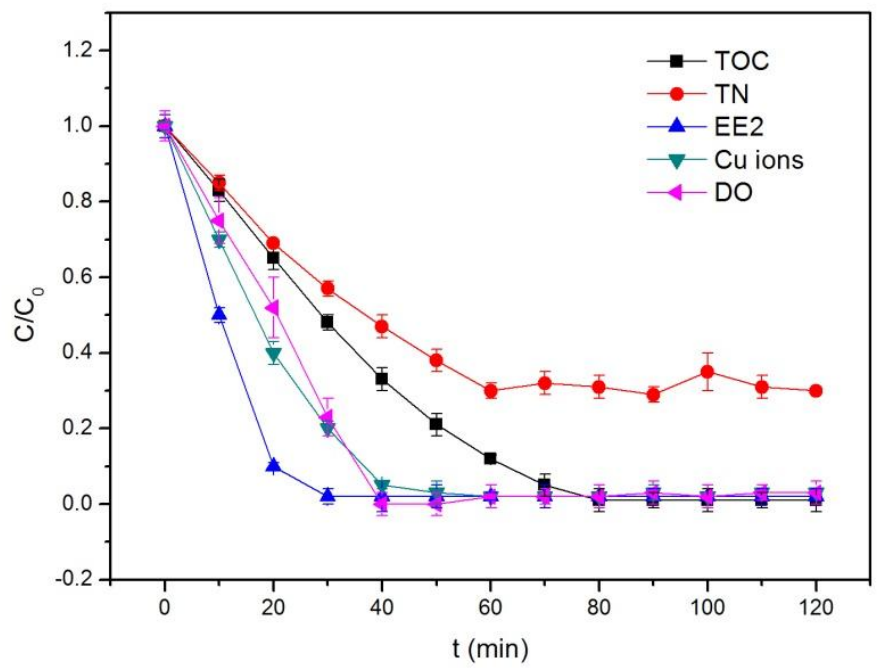

Fig. 3.

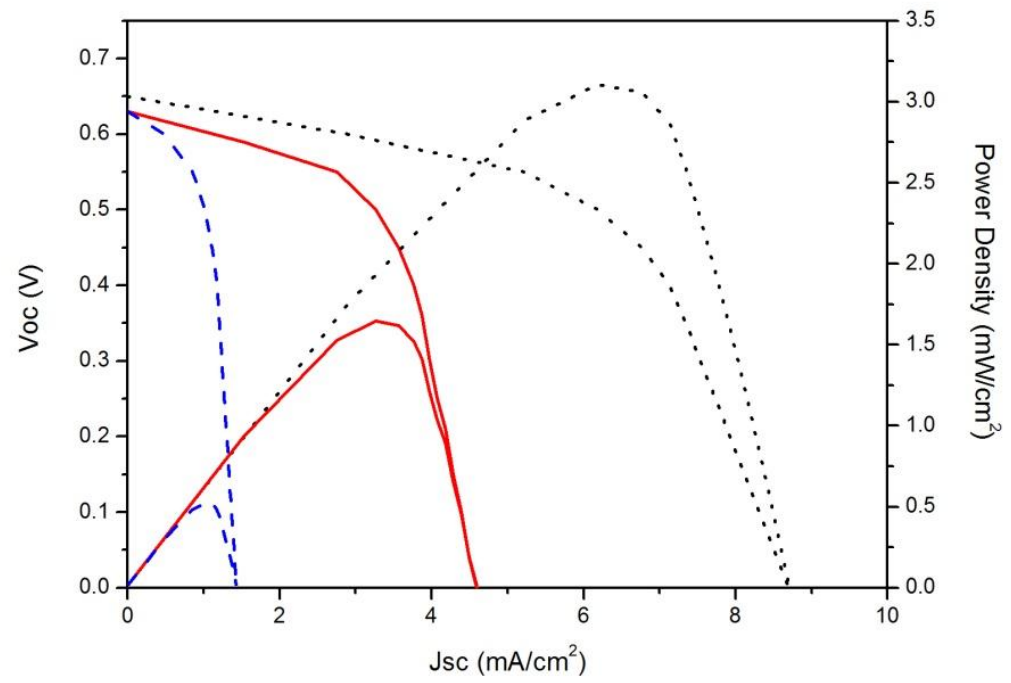

Fig. 4. 


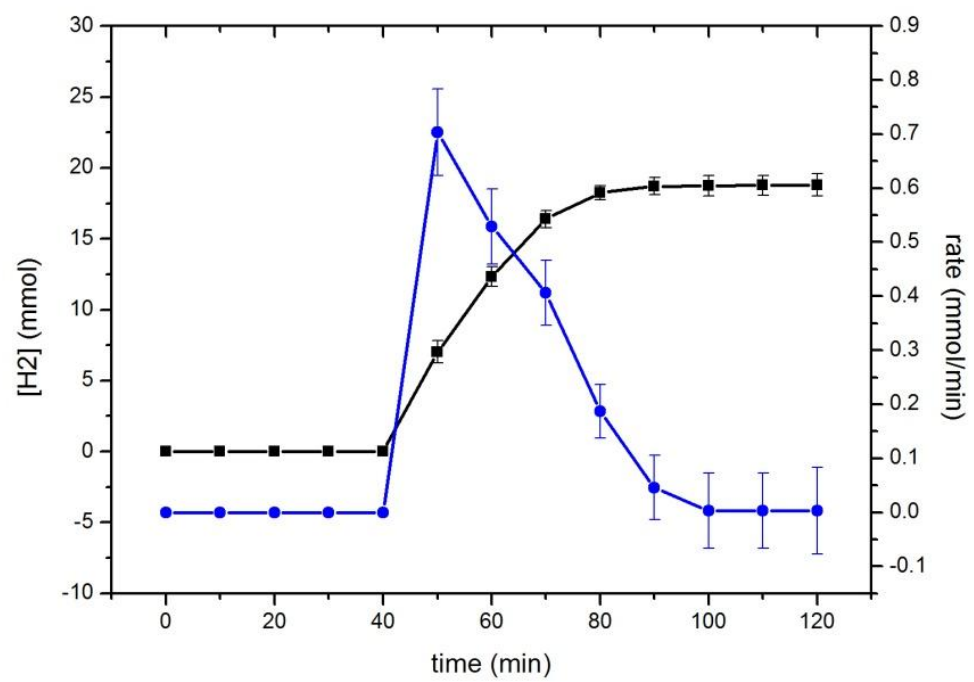

Fig. 5. 


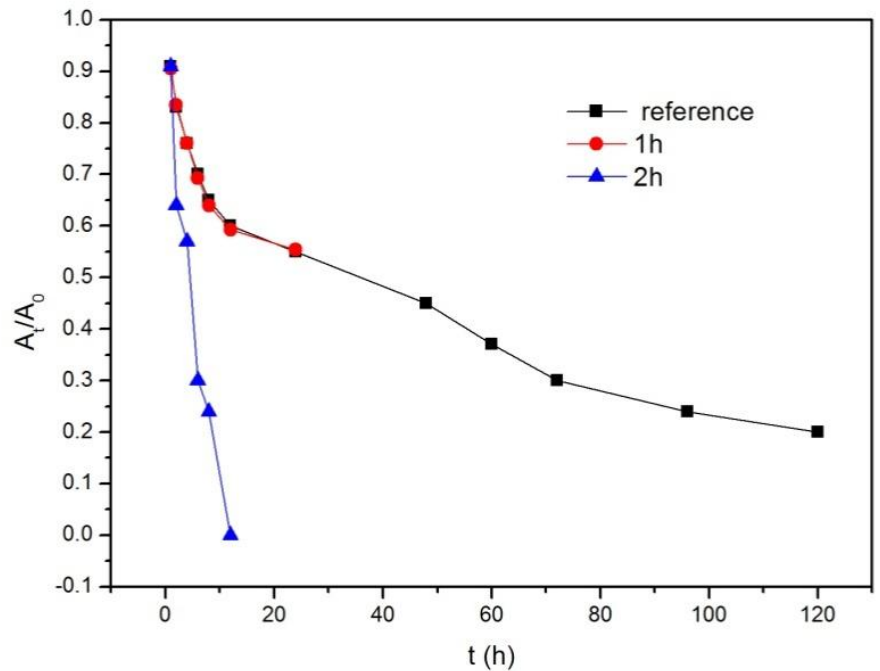

Fig. 6. 

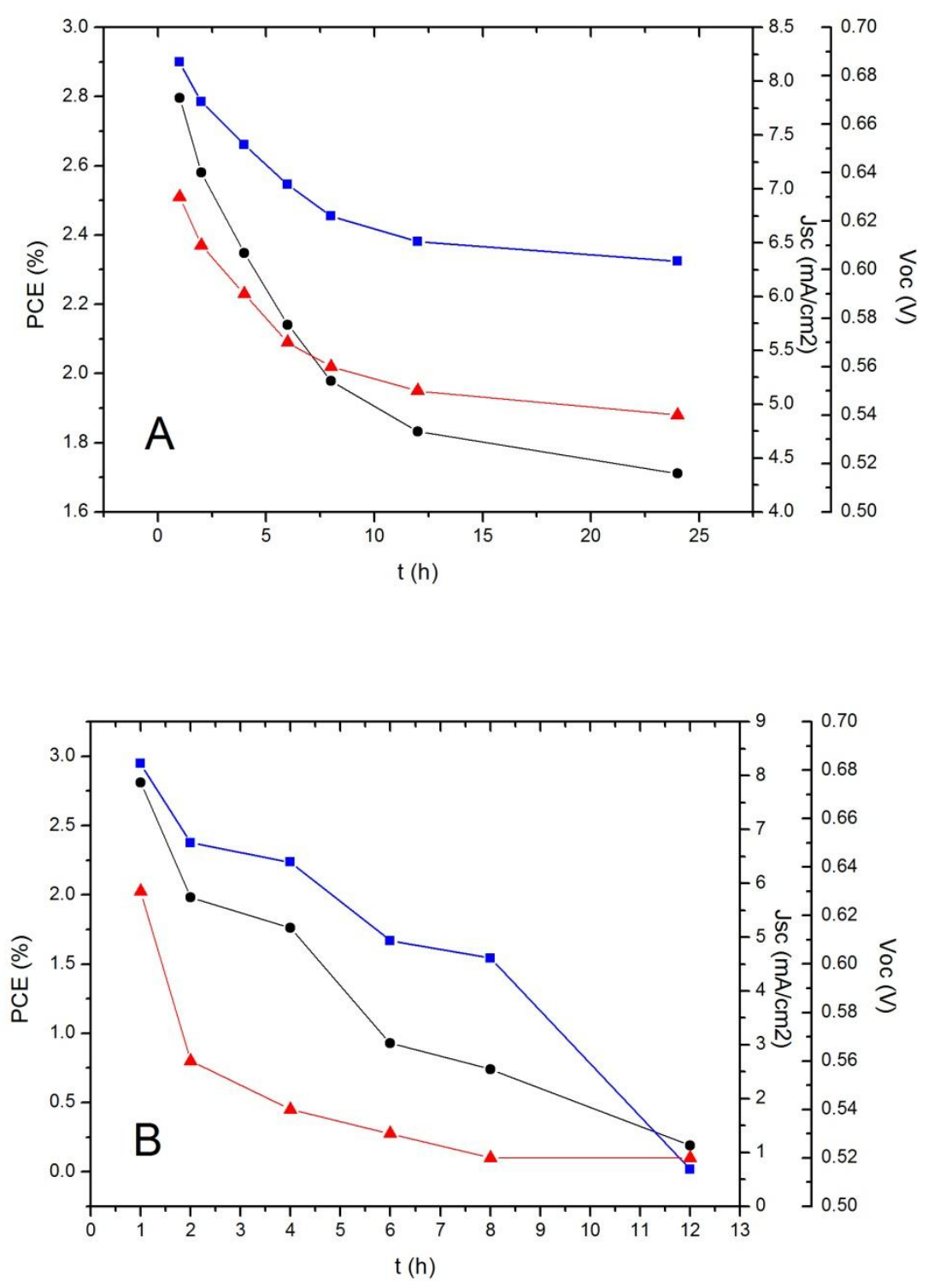

Fig. 7. 
Graphical abstract
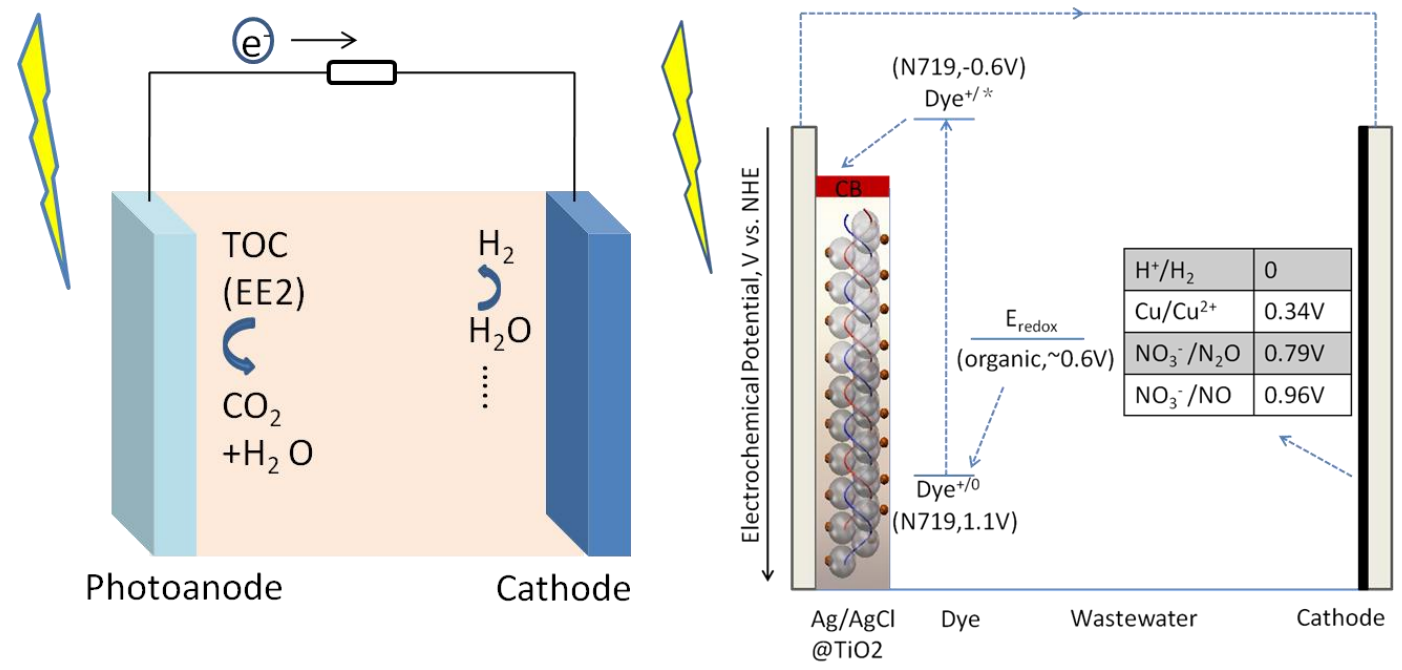


\section{Highlights:}

- Environmental remediation with simultaneous generation of renewable energy

- Renewable energy is produced from urban wastewater effluents

- Simultaneous water detoxification and hydrogen/electricity production

- Urban wastewater effluent provides the electrolyte in the dye sensitised solar cell

- Photoanode made by a novel plasmonic $\mathrm{Ag} / \mathrm{AgCl} @$ chiral $\mathrm{TiO}_{2}$ nanofibers 
Supplementary Material
Click here to download Supplementary Material: Revised Supplementary Material (10.25).doc

Supplementary Material
Click here to download Supplementary Material: Revised Supplementary Material (10.25).doc

作

$\sqrt{2}$

(1) (1)

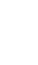
(1) 